\title{
Synthesis and characterization of amphiphilic poly(pseudo-amino acid) polymers containing a nucleobase
}

\author{
Ren-Shen Lee, Kang-Yu Peng, Shiu-Wei Wang and You-Zhen Li
}

In this study, we developed novel bioresorbable amphiphilic poly(pseudo-amino acid)s containing nucleobases. These polymers were synthesized by the condensation polymerization of $\mathrm{N}$-benzyloxycarbonyl-4-hydroxyl-L-proline (NZHpr), followed by the coupling of an alkynyl-functionalized nucleobase derivative to the azido-end group of $\mathrm{PNZHpr}_{\mathrm{n}}$. These polymers were characterized by ultraviolet-visible, fluorescence, nuclear magnetic resonance, infrared spectroscopy and gel permeation chromatography. The nucleobase-terminated $\mathrm{PNZHpr}_{\mathrm{n}}$ polymers formed micelles in an aqueous phase. The critical micelle concentrations ranged from 1.51 to $16.90 \mathrm{mg} \mathrm{I}^{-1}$. Vesicular or spherical micellar structures were observed, depending on the nucleobase coupled. Nucleobase-PNZHpr ${ }_{n}$ selectively bound to complementary small molecules. The micelles were observed to release drugs rapidly in an acidic environment. An in vitro cell viability assay indicated that nucleobase-terminated $\mathrm{PNZHpr}_{\mathrm{n}}$ exhibited low cytotoxicity. doxorubicin (DOX)-loaded micelles facilitated drug release more effectively compared with free DOX based on the uptake by human cervical cancer (HeLa) cells. Furthermore, these micelles were primarily retained in the cytoplasm, whereas free DOX tended to accumulate in the nuclei.

Polymer Journal (2014) 46, 710-721; doi:10.1038/pj.2014.52; published online 16 July 2014

\section{INTRODUCTION}

The self-association of amphiphilic block copolymers into supramolecular assemblies has been well documented in the scientific literature. This phenomenon is attracting increasing interest because of its application in the development of functional nanofabricated materials. ${ }^{1-3}$ In select solvents, amphiphilic block copolymers can form polymeric micelles and polymeric aggregates, consisting of a core of the insoluble macromolecular component surrounded by a shell of the solvated 'block'. These compounds are potential carrier systems for hydrophobic drugs and other active molecules. ${ }^{4-7}$ Oligonucleobase moieties have been increasingly used in materials science in recent years. ${ }^{8-14}$ Several researchers have elegantly demonstrated the application of oligonucleotides as versatile building blocks for synthesizing, controlled drug delivery systems and tissue engineering scaffolds. In biological systems, complementary hydrogen-bonding interactions and molecular recognition, which occurs between the adenine-thymine and guanine-cytosine base pairs in DNA, are paramount. Various synthetic polymers have been functionalized with self-complementary nucleobases, such as adenine, thymine and uracil. ${ }^{15-17}$ However, reports on incorporating a heteronucleobase unit in biocompatible materials are rare.

Poly(pseudo-amino acid)s are a group of biodegradable or bioresorbable polymers that differ from conventional poly(amino acid)s in that the polymer backbone is formed using the side-chain functional groups on monomeric $\alpha$-L-amino acids or dipeptides. This approach enables the creation of polymers from naturally occurring metabolites without the potential disadvantages of conventional poly(amino acid)s (for example, poor mechanical strength and enzymatic degradation). ${ }^{18}$ To our knowledge, nucleobase-installed poly(pseudo-amino acid)s have not been investigated.

This study investigated the synthesis of an amphiphilic biodegradable nucleobase-installed poly(pseudo-amino acid) as a novel precursor for colloidal (drug) delivery systems. This polymer consists of a hydrophobic, biodegradable poly( $N$-benzyloxycarbonyl 4-hydroxyl-L-proline) $\left(\mathrm{PNZHpr}_{\mathrm{n}}\right)$ segment and an end-capped nucleobase derivative as the hydrophilic segment. The amphiphilic and selfassembling properties of the copolymer were examined. Finally, fluorescent imaging studies of the internalization of polymeric micelles encapsulating doxorubicin (DOX) into HeLa cells suggested that the polymer could potentially be useful as a fluorescent probes for optical bioimaging.

\section{EXPERIMENTAL PROCEDURES}

\section{Materials}

Trans-4-hydroxy-N-benzyloxycarbonyl-L-proline (NZHpr), 2-(2-chloroethoxy) ethanol, propargyl bromide, sodium azide, indomethacin (IMC) and pyrene were purchased from Aldrich Chemical Co. (Milwaukee, WI, USA). Uracil (Ura), thymine (Thy) and adenine (Ade) were purchased from Sigma Chemical Co. (Saint Louis, MO, USA). N-(2-propynyl) nucleobases were 
prepared according to the modified method described in the relevant literature. ${ }^{11}$ DOX hydrochloride (DOX.HCl 99\%) (Sigma Chemical Co.) was deprotonated according to a procedure in the literature to obtain hydrophobic DOX. ${ }^{19}$ Stannous octoate $\left(\mathrm{SnOct}_{2}\right)$ was purchased from Strem Chemical Co. (Newburyport, MA, USA). Organic solvents, such as tetrahydrofuran, methanol, chloroform, $\mathrm{N}, \mathrm{N}$-dimethyl formamide (DMF), dimethylsulfoxide (DMSO) and $n$-hexane, of high-pressure liquid chromatography grade, were purchased from Merck Chemical (Darmstad, Germany). Dulbecco's modified Eagle's medium (DMEM)/F12 1:1 medium, trypsin and 100X antibioticantimycotic were purchased from Invitrogen (Carlsbad, CA, USA). Fetal bovine serum (FBS) was obtained from Biological Industry (Kibbutz Beit Haemek, Israel). A CellTiter 96 AQueuous One Solution kit was obtained from Promega (Fitchburg, WI, USA). Ultrapure water was obtained using a Milli-Q Plus (Waters, Milford, MA, USA).

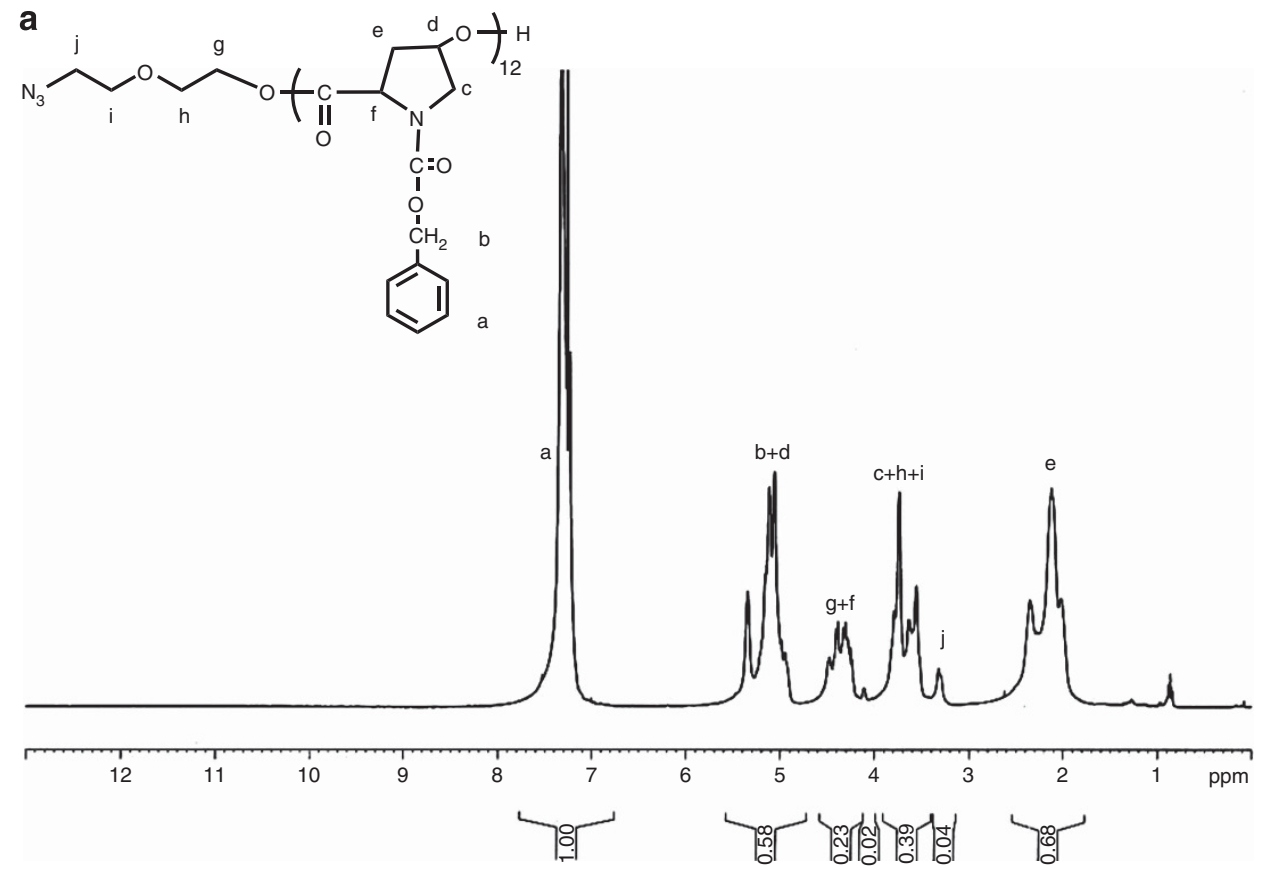

b

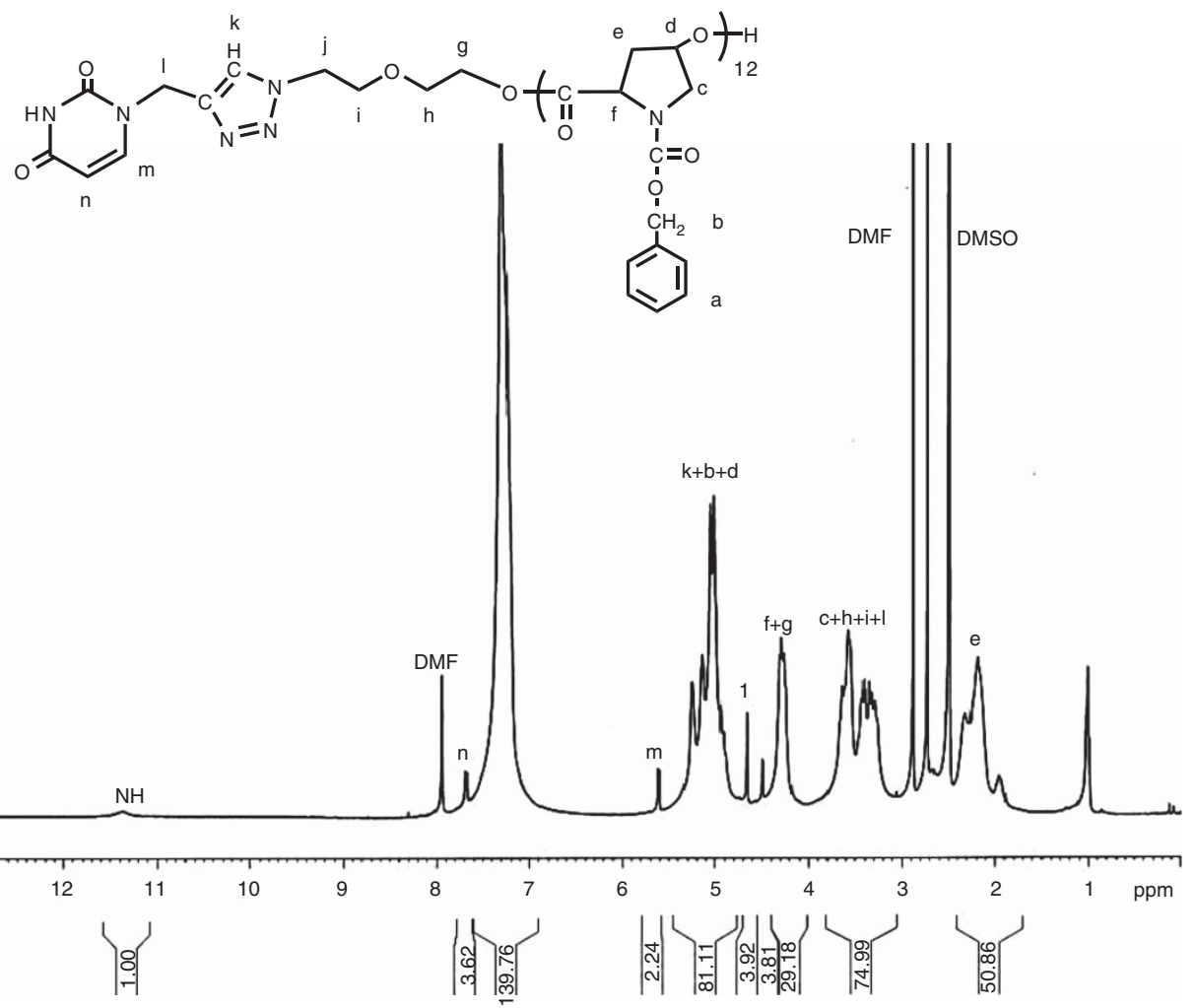

Figure $1{ }^{1} \mathrm{H}$ NMR spectra of (a) $\mathrm{N}_{3}\left(\mathrm{CH}_{2} \mathrm{CH}_{2} \mathrm{O}\right)_{2}-\mathrm{PNZHpr}_{12}$ and (b) Ura-PNZHpr 12 . 


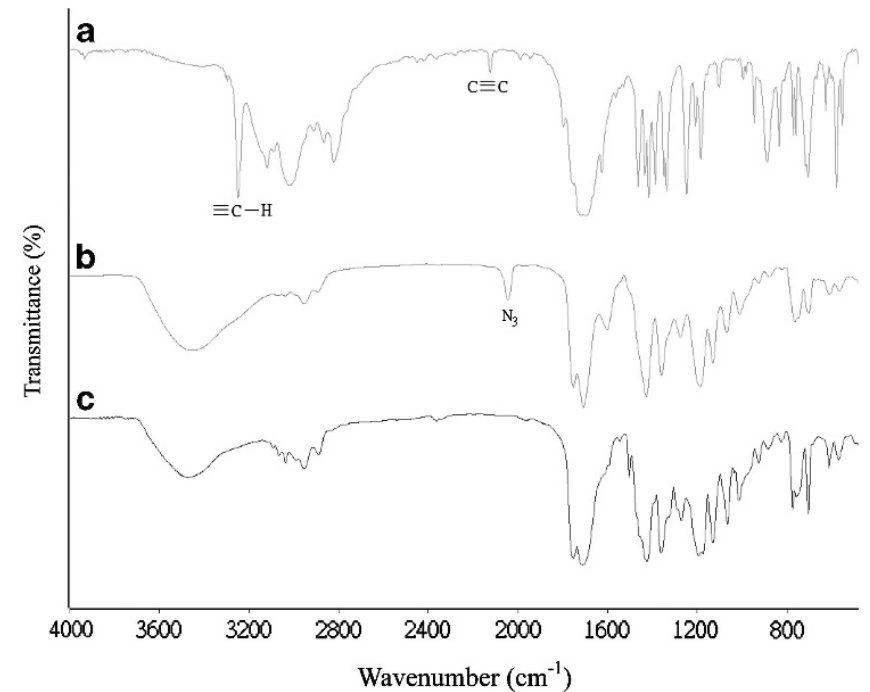

Figure 2 IR spectra of (a) $\mathrm{N}$-propynyl uracil, (b) $\mathrm{N}_{3}\left(\mathrm{CH}_{2} \mathrm{CH}_{2} \mathrm{O}\right)_{2}-\mathrm{PNZHpr}_{12}$, and (c) Ura-PNZHpr 12. A full color version of this figure is available at the Polymer Journal online.<smiles>[Z7]C(=O)OCc1ccccc1</smiles>

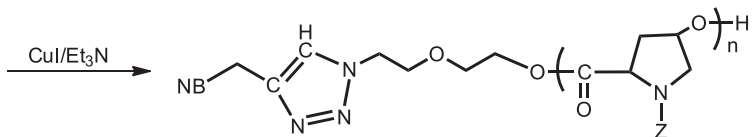<smiles>Cc1cn(C)c(=O)[nH]c1=O</smiles>

Scheme 1 Synthesis of nucleobase-terminated poly(pseudo-amino acid).

\section{Synthesis of $\mathrm{N}_{3}\left(\mathrm{CH}_{2} \mathrm{CH}_{2} \mathrm{O}\right)_{2}-\mathrm{PNZHpr}_{\mathrm{n}}$}

Poly(pseudo-amino acid)s of various contents were synthesized according to a method reported in a previous study. ${ }^{20} \mathrm{Cl}\left(\mathrm{CH}_{2} \mathrm{CH}_{2} \mathrm{O}\right)_{2}-\mathrm{PNZHpr}_{n}$ was synthesized by the condensation polymerization of NZHpr with the hydroxyl-terminated initiator 2-(2-chloroethoxy)ethanol in chlorobenzene using $\mathrm{SnOct}_{2}(3 \mathrm{wt} \%)$ as the catalyst. All of the monomers were dried in a vacuum oven before use. The reaction mixture was refluxed for $24 \mathrm{~h}$ in a nitrogen atmosphere. The solution was concentrated using a vacuum rotary evaporator. The resulting product was dissolved in $\mathrm{CHCl}_{3}$ and then precipitated into excess $n$-hexane/ethyl ether ( $\mathrm{v} / \mathrm{v}$ 5:1) while stirring. The purified polymer was dried in vacuo at $50{ }^{\circ} \mathrm{C}$ for $24 \mathrm{~h}$ and then analyzed. The yields ranged from $85 \%$ to $98 \%$. Subsequently, $\mathrm{Cl}\left(\mathrm{CH}_{2} \mathrm{CH}_{2} \mathrm{O}\right)_{2}-\mathrm{PNZHpr}_{n}$ was dissolved in $10 \mathrm{ml}$ of DMF in a glass reactor, $\mathrm{NaN}_{3}$ was then added to the

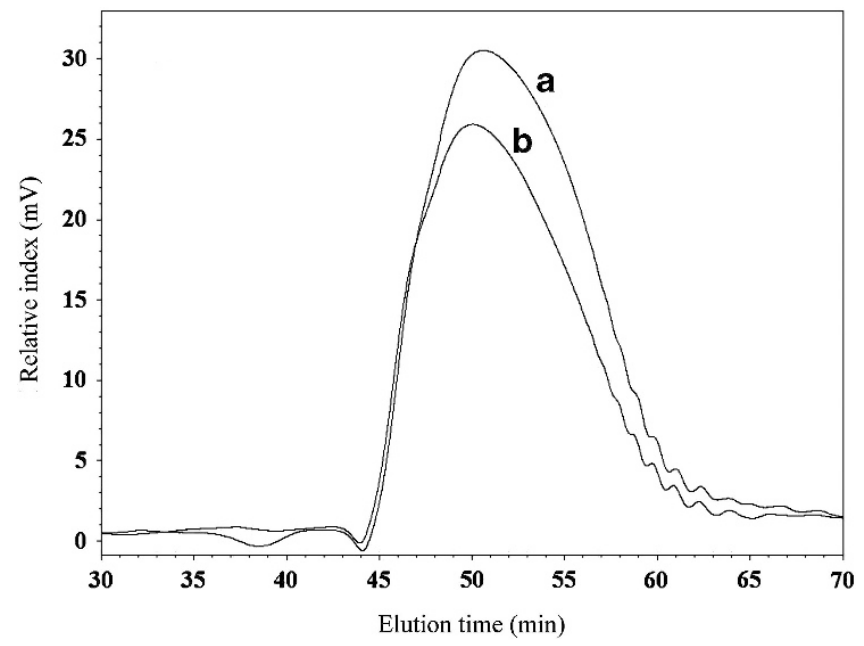

Figure 3 GPC curves of (a) $\mathrm{N}_{3}\left(\mathrm{CH}_{2} \mathrm{CH}_{2} \mathrm{O}\right)_{2}-\mathrm{PNZHpr}_{12}$, and (b) UraPNZHpr 12 .

Table 1 Molecular weight and properties of nucleobase coupling $\mathrm{PNZHpr}_{\mathrm{n}}$

\begin{tabular}{lccccc}
\hline Polymer $^{\mathrm{a}}$ & Yield $^{\mathrm{b}}(\%)$ & $M_{n, N M R^{\mathrm{c}}}$ & $M_{n, t h^{\mathrm{d}}}$ & $M_{n, G P C}{ }^{\mathrm{e}}$ & $M_{w} M_{n}{ }^{\mathrm{e}}$ \\
\hline Ura-PNZHpr & 60 & 1756 & 1763 & 1280 & 1.01 \\
Ade-PNZHpr $_{6}$ & 55 & 1786 & 1786 & 1440 & 1.04 \\
Thy-PNZHpr $_{6}$ & 63 & 1770 & 1777 & 1390 & 1.03 \\
Ura-PNZHpr $_{12}$ & 69 & 3245 & 3245 & 2830 & 1.25 \\
Ade-PNZHpr $_{12}$ & 80 & 3069 & 3268 & 2260 & 1.60 \\
Thy-PNZHpr $_{12}$ & 70 & 3259 & 3259 & 2080 & 1.57 \\
\hline
\end{tabular}

Abbreviations: Ade, adenine; GPC, gel permeation chromatography; NMR, nuclear magnetic resonance; PNZHpr, polymerization of $\mathrm{N}$-benzyloxycarbonyl-4-hydroxyl-L-proline; Thy, thymine Ura, uracil.

asubscript refers to the degree of polymerization.

bIsolated yield.

${ }^{\text {CDetermined by }}{ }^{1} \mathrm{H}$ NMR spectroscopy of nucleobase-terminated $\mathrm{PNZHPr}_{\mathrm{n}}$.

${ }^{\mathrm{d}} M_{\mathrm{n}, \mathrm{th}}=M_{\mathrm{n}, \mathrm{PNZH} \text { prn }}+M_{2 \text {-propynyl nucleobase }}$

eDetermined by GPC using $\mathrm{CHCl}_{3}$ as the eluent.

solution and the mixture was stirred at room temperature overnight. Insoluble salts were removed by filtration, and the DMF was removed in vacuo. The resulting product was dissolved in $\mathrm{CHCl}_{3}$ and then precipitated into excess $n$-hexane/ethyl ether (v/v 5:1) while stirring. The purified polymer was dried in vacuo at $50{ }^{\circ} \mathrm{C}$ for $24 \mathrm{~h}$ and then analyzed. The yields ranged from $70 \%$ to $90 \%$. Figure la shows a representative ${ }^{1} \mathrm{H}$ nuclear magnetic resonance (NMR) spectrum of $\mathrm{N}_{3}\left(\mathrm{CH}_{2} \mathrm{CH}_{2} \mathrm{O}\right)_{2}-\mathrm{PNZHpr}_{12}$. A representative Fourier transform infrared (FT-IR) spectrum of $\mathrm{N}_{3}\left(\mathrm{CH}_{2} \mathrm{CH}_{2} \mathrm{O}\right)_{2}-\mathrm{PNZHpr}_{12}$ is shown in Figure $2 \mathrm{~b}$.

\section{Clicking of $\mathrm{N}$-(2-propynyl)-nucleobase to $\mathrm{N}_{3}\left(\mathrm{CH}_{2} \mathrm{CH}_{2} \mathrm{O}\right)_{2}$-PNZHpr}

Three types of $\mathrm{N}$-(2-propynyl)-nucleobase ( $\mathrm{N}$-(2-propynyl)-uracil, $\mathrm{N}$-(2propynyl)-thymine and $\mathrm{N}$-(2-propynyl)-adenine) were prepared using a method similar to that previously described. ${ }^{11}$ We used a typical procedure for clicking the $\mathrm{N}$-(2-propynyl)-nucleobase to $\mathrm{N}_{3}\left(\mathrm{CH}_{2} \mathrm{CH}_{2} \mathrm{O}\right)_{2}-\mathrm{PNZHpr}_{\mathrm{n}}$. First, we dissolved $282.4 \mathrm{mg}(0.19 \mathrm{mmol})$ of $\mathrm{N}_{3}\left(\mathrm{CH}_{2} \mathrm{CH}_{2} \mathrm{O}\right)_{2}-\mathrm{PNZHpr}_{12}$ and $28.5 \mathrm{mg}(0.19 \mathrm{mmol})$ of $\mathrm{N}$-(2-propynyl)-uracil in $5 \mathrm{ml}$ of dry tetrahydrofuran in a nitrogen atmosphere. After the compounds were completely dissolved, $3.5 \mathrm{mg}$ of $\mathrm{CuI}$ and $1.9 \mathrm{mg}$ of $\mathrm{Et}_{3} \mathrm{~N}$ were added to the flask. The flask was then heated at $60^{\circ} \mathrm{C}$ for $72 \mathrm{~h}$. After the reaction solution was filtered, end-capped Ura-PNZHpr 12 was obtained as a solid by precipitation into excess $n$-hexane/ ethyl ether (v/v 5:1) while stirring. The purified polymer was dried in vacuo at $50{ }^{\circ} \mathrm{C}$ for $24 \mathrm{~h}$ and then analyzed. The yields ranged between $55 \%$ and $80 \%$. Figures $1 \mathrm{~b}$ and $2 \mathrm{c}$ show representative ${ }^{1} \mathrm{H}$ NMR and FT-IR spectra of UraPNZHpr $_{12}$. 

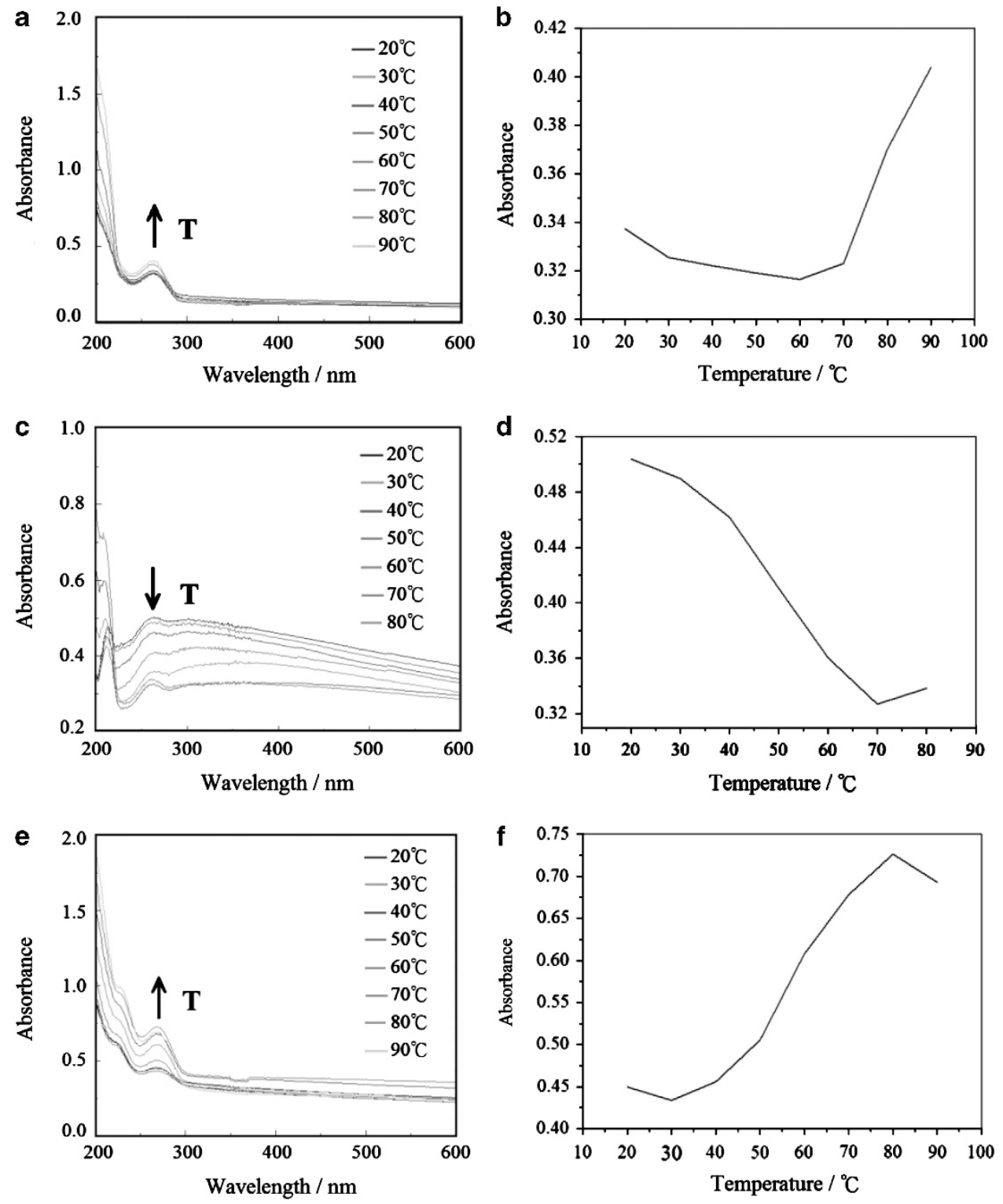

Figure 4 Temperature-dependent UV-vis spectra and thermal denaturation at $5 \times 10^{-5} \mathrm{M}$ of Ura-PNZHpr 12 (a, b), Ade-PNZHpr 12 (c, d) and Thy-PNZHpr 12 $(\mathbf{e}, \mathbf{f})$ in water. A full color version of this figure is available at the Polymer Journal online.

Ura-PNZHpr ${ }_{12}{ }^{1} \mathrm{H}$ NMR (DMSO- $d_{6}, \delta$ ): 11.2-11.5 (1H, -CONHCO-), 7.69 $(1 \mathrm{H}, \mathrm{d},-\mathrm{NCH}-), 6.99-7.60(60 \mathrm{H}, \mathrm{bs}$, phenyl -CH-), $5.59(1 \mathrm{H}, \mathrm{d},-\mathrm{COCH}-)$, $5.26(1 \mathrm{H}, \mathrm{s},-\mathrm{C}=\mathrm{CH}-), 4.80-5.19\left(36 \mathrm{H}, \mathrm{m},-\mathrm{CH}_{2} \mathrm{Ph},-\mathrm{CHO}-\right), 4.50-4.70(2 \mathrm{H}$, s, $\left.-\mathrm{NCH}_{2}-\right), 4.15-4.45\left(14 \mathrm{H}, \mathrm{m},-\mathrm{CH}_{2} \mathrm{CO}-,-\mathrm{COCHN}-\right), 3.16-3.82(30 \mathrm{H}, \mathrm{m}$, $\left.-\mathrm{CH}_{2} \mathrm{~N}-\right), 2.02-2.41\left(24 \mathrm{H}, \mathrm{m},-\mathrm{CH}_{2}-\right)$ p.p.m.

Thy-PNZHpr $12{ }^{1} \mathrm{H}$ NMR $\left(\mathrm{CDCl}_{3}, \delta\right): 7.14-7.55(61 \mathrm{H}, \mathrm{m}$, pyrimidine -CH-, phenyl - $\mathrm{CH}-), 5.38(1 \mathrm{H}, \mathrm{s},-\mathrm{C}=\mathrm{CH}-), 4.82-5.30\left(36 \mathrm{H}, \mathrm{m},-\mathrm{CH}_{2} \mathrm{Ph},-\mathrm{CHO}-\right)$, 4.19-4.61 (14H, m, - $\left.\mathrm{CH}_{2} \mathrm{CO}-,-\mathrm{COCHN}-\right), 3.42-4.01\left(30 \mathrm{H}, \mathrm{m},-\mathrm{CH}_{2} \mathrm{~N}-\right)$, $3.21-3.42\left(2 \mathrm{H}, \mathrm{m},-\mathrm{CH}_{2} \mathrm{~N}-\right), 1.91-2.49\left(24 \mathrm{H}, \mathrm{m},-\mathrm{CH}_{2}-\right), 1.22\left(3 \mathrm{H}, \mathrm{s},-\mathrm{CH}_{3}\right)$ p.p.m.

Ade-PNZHpr ${ }_{12}{ }^{1} \mathrm{H}$ NMR (DMSO- $\left.d_{6}, \delta\right): 8.08 \quad(1 \mathrm{H}$, bs, $-\mathrm{N}=\mathrm{CHN}-$ ), 6.98-7.52 $(61 \mathrm{H}, \mathrm{m},=\mathrm{NCH}=\mathrm{N}-$, phenyl $-\mathrm{CH}-), 5.26(1 \mathrm{H}, \mathrm{s},-\mathrm{C}=\mathrm{CH}-)$, $4.81-5.19\left(36 \mathrm{H}, \mathrm{m},-\mathrm{CH}_{2} \mathrm{Ph},-\mathrm{CHO}-\right), 4.15-4.41 \quad\left(14 \mathrm{H}, \mathrm{m},-\mathrm{CH}_{2} \mathrm{CO}-\right.$, -COCHN-), 3.12-3.85 (32 H, m, - $\left.\mathrm{CH}_{2} \mathrm{~N}-\right), 2.05-2.40\left(24 \mathrm{H}, \mathrm{m},-\mathrm{CH}_{2}-\right)$ p.p.m.

\section{Characterization}

We recorded ${ }^{1} \mathrm{H}$ NMR spectra at $500 \mathrm{MHz}$ using a Bruker WB/DMX-500 spectrometer (Bruker, Ettlingen, Germany), and chloroform ( $\delta=7.24$ p.p.m.) was used as an internal standard in chloroform- $d\left(\mathrm{CDCl}_{3}\right)$. IR spectra were measured using a Bruker TENSOR 27 FT-IR spectrophotometer (Bruker). Samples were either neatly placed on $\mathrm{NaCl}$ plates or pressed into $\mathrm{KBr}$ pellets. The number and weight-average molecular weights $\left(M_{\mathrm{n}}\right.$ and $M_{\mathrm{w}}$ respectively) of the polymer were determined by gel permeation chromatography (GPC), which was conducted using an high-pressure liquid chromatography system equipped with a model PU-2031 refractive-index detector (Jasco, Tokyo, Japan) and Jordi Gel polydivinyl benzene columns with pore sizes of 100, 500 and $1000 \AA$. Chloroform was used as the eluent at a flow rate of $0.5 \mathrm{ml} \mathrm{min}{ }^{-1}$. Polyethylene glycol standards of low dispersity (Polymer Sciences, Mainz, Germany) were used to generate a calibration curve. Data were recorded and manipulated using a Windows-based software package (Scientific Information Service, Skillman, NJ, USA).

Temperature-dependent ultraviolet-visible (UV-vis) measurements Spectra were recorded on a Jasco V-550 spectrophotometer equipped with an ETC-505T temperature controller (Jasco). Samples were dissolved in MilliQ water to a concentration of $5 \times 10^{-5} \mathrm{M}$ and were placed in $1-\mathrm{cm}$ quartz 

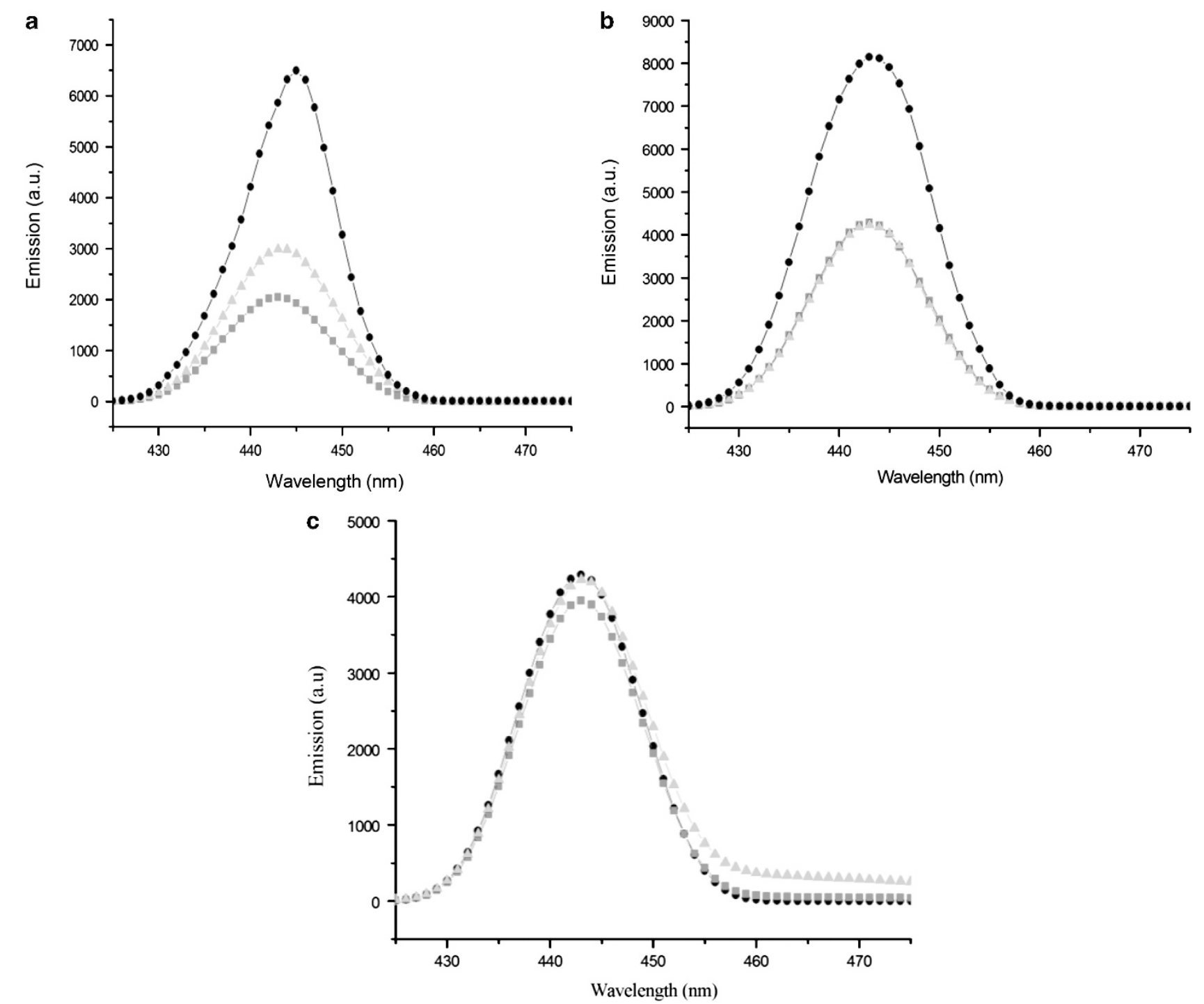

Figure 5 Fluorescence spectra of nucleobase-PNZHpr $\left(\right.$ red: $10^{-4} \mathrm{M}, \mathbf{\square}$ ) with adenosine (black: $10^{-3} \mathrm{M}$, - ; green: $10^{-4} \mathrm{M}, \mathbf{\Delta}$ ) for: (a) Ura-PNZHpr 12 , (b) Thy-PNZHpr 12 and (c) Ade-PNZHpr 12 . Emission spectra were obtained by excitation at $436 \mathrm{~nm}$. A full color version of this figure is available at the Polymer Journal online.

cuvette. Spectra were measured while increasing the temperature from $20^{\circ} \mathrm{C}$ to $90^{\circ} \mathrm{C}$ (heating rate: $1{ }^{\circ} \mathrm{C} \mathrm{min}^{-1}$ ). The thermal denaturation temperature of nucleobase-PNZHpr ${ }_{n}$ polymers were determined based on the temperature at which a $50 \%$ increase (or decrease) in the absorbance occurred at 263,267 and $264 \mathrm{~nm}$ for Ura-PNZHpr 12 , Thy-PNZHpr 12 and Ade-PNZHpr 12 , respectively.

\section{Fluorescence measurements}

Fluorescence measurements were conducted using pyrene as a probe to investigate micelle formation. ${ }^{21}$ The pyrene fluorescence spectra were recorded on an F-4500 spectrofluorometer (Hitachi High-Technologies Co. Tokyo, Japan). Square quartz cells of $1.0 \mathrm{~cm} \times 1.0 \mathrm{~cm}$ were used. First, we recorded the fluorescence spectra of pyrene in an aqueous solution at room temperature, using a fluorescence spectrophotometer. Sample solutions were then prepared by adding known amounts of pyrene in acetone to a series of flasks. After the acetone had completely evaporated, measured amounts of nucleobase-PNZHpr $r_{n}$ micelle solutions at various concentrations, ranging from 0.0183 to $300 \mathrm{mgl}^{-1}$, were added to each flask and mixed by vortexing. The pyrene concentration in the final solution was $6.1 \times 10^{-7} \mathrm{M}$. The flasks were allowed to stand overnight at room temperature to equilibrate the pyrene and the micelles. For the fluorescence spectra, $\lambda_{\mathrm{ex}}=339 \mathrm{~nm}$, and for the excitation spectra, $\lambda_{\mathrm{em}}=390 \mathrm{~nm}$.

\section{Preparation of polymeric micelles}

Polymeric micelles of nucleobase-PNZHpr ${ }_{n}$ polymers were prepared using a dialysis-based method. ${ }^{22}$ Briefly, a solution of nucleobase-PNZHpr ${ }_{n}$ polymer (30 $\mathrm{mg})$ in DMF $(5 \mathrm{ml})$ was placed in a dialysis bag (molecular weight cutoff $(\mathrm{MWCO})=3500)$ and dialyzed against deionized (DI) water at ambient temperature for $24 \mathrm{~h}$. The water was replaced at 2 -h intervals.

\section{Dynamic light-scattering (DLS) measurements}

Micelle size and size distribution were investigated by DLS (Zetasizer Nano ZS, Malvern, UK) with an argon laser operating at $632.8 \mathrm{~nm}$ and a fixed scattering angle of $90^{\circ}$ at $20^{\circ} \mathrm{C}$. Measurements were recorded after the aqueous micellar solution $\left(\mathrm{C}=0.3 \mathrm{gl}^{-1}\right)$ was filtered using a microfilter with an average pore size of $0.2 \mu \mathrm{m}$ (Advantec MFS, Inc., Dublin, CA, USA). The average size distribution of the aqueous micellar solution was determined using the CONTIN program developed by Provencher and Hendrix. ${ }^{23}$ 


\section{Transmission electron microscopy measurements}

Microscopic images of micelles were observed using transmission electron microscopy (JEM 1200-EXII, JEOL, Tokyo, Japan). Drops of micelle solution $\left(0.3 \mathrm{gl}^{-1}\right.$, not containing a staining agent) were placed on a carbon film coated on a copper grid and then dried at room temperature. The observations were made at an accelerating voltage of $100 \mathrm{kV}$.

\section{Determination of drug-loading content and drug-entrapment efficiency}

Nucleobase-PNZHpr ${ }_{n}$ (50-fold critical micelle concentration (CMC) value) was dissolved in $6 \mathrm{ml}$ of methylene chloride by using oil-in-water evaporation. Subsequently, IMC, an anti-inflammatory drug, was added to the polymer at a 1:1 weight ratio to serve as a model drug. The solution was added dropwise to $150 \mathrm{ml}$ of distilled water containing $1 \mathrm{wt} \%$ poly(vinyl alcohol) and vigorously stirred. Poly(vinyl alcohol) was used as a surfactant to reduce micelle aggregation. Sonication was applied for $1 \mathrm{~h}$ at ambient temperature to reduce the droplet size. The emulsion was stirred at ambient temperature overnight to evaporate the methylene chloride. The unloaded IMC residue was removed by filtration using a Teflon filter (Whatman, Maidstone, UK) with an average pore size of $0.45 \mu \mathrm{m}$. Micelles were subsequently obtained by vacuum drying. A weighed amount of micelles were then disrupted by adding a 10-fold excess volume of DMF. The drug content was assayed spectrophotometrically at $320 \mathrm{~nm}$ using a diode array UV-vis spectrophotometer.

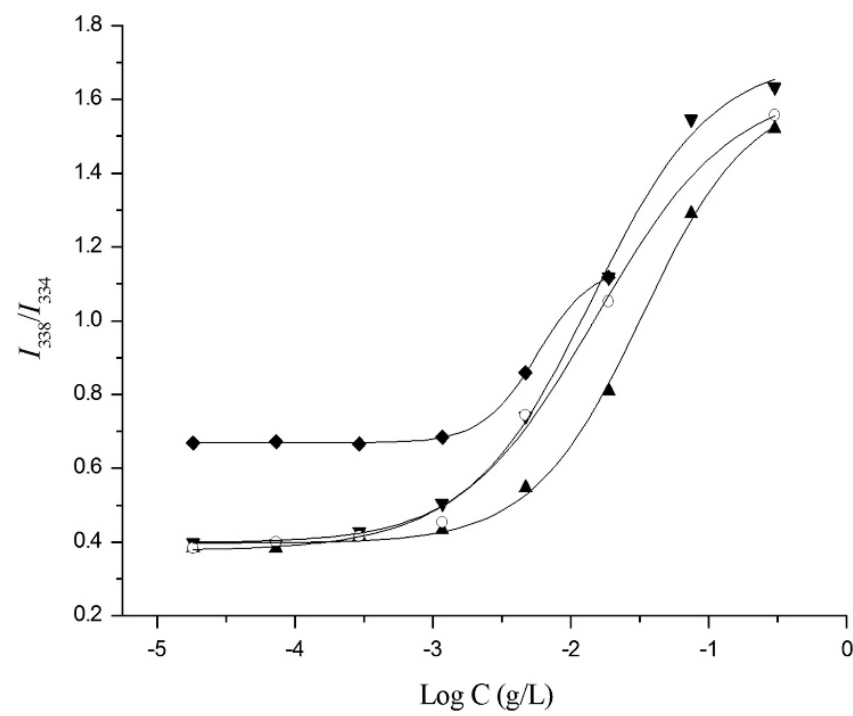

Figure 6 Plot of the $I_{338} / /_{334}$ intensity ratio (from pyrene exciation spectra; pyrene concentration $\left.=6.1 \times 10^{-7} \mathrm{M}\right)$ versus the logarithm of the concentration (Log C) for $(\mathbf{\Delta})$ Ade-PNZHpr $12,(\diamond)$ Ura-PNZHpr $_{6},(\boldsymbol{\nabla})$ Ura$\mathrm{PNZHpr}_{12}$ and $(\mathrm{O})$ Thy-PNZHpr 12 polymer micelles.
DOX-loaded micelles were prepared by a dialysis method. Briefly, DOX.HCl $(5 \mathrm{mg})$ and $3 \mathrm{~mol}$ of triethyl amine (TEA) were dissolved in DMSO $(1 \mathrm{ml})$ and added to a tetrahydrofuran $(2 \mathrm{ml})$ solution containing Nucleobase-PNZHpr $(5 \mathrm{mg})$. The mixture was added slowly to $10 \mathrm{ml}$ of water and ultrasonicated for $10 \mathrm{~min}$. After being stirred for an additional $2 \mathrm{~h}$, the solution was transferred to a $1000 \mathrm{Da}$ MWCO dialysis bag and dialyzed for $24 \mathrm{~h}$ to remove the free DOX and organic solvent. The final solution in the dialysis bag was freeze-dried to obtain red micelles. To determine the drug-loading content, the DOX-loaded micelles were dissolved in DMSO and the absorbance at $480 \mathrm{~nm}$ was measured to determine the DOX concentration based on a standard calibration curve obtained from free DOX in DMSO.

The following equations were used to calculate the drug-loading content and drug-entrapment efficiency:

Drug - loading content $(\%)$

$=($ weight of drug in the micelles $/$ weight of micelles $) \times 100$

Drug entrapment efficiency $(\%)$

$=($ weight of drug in the micelles/weight of drug provided initially $) \times 100$

\section{In vitro drug release studies}

Appropriate amounts of IMC-loaded micelles $(110.2 \mathrm{mg})$ were precisely weighted and suspended in $10 \mathrm{ml}$ of phosphate-buffered solution (PBS) $(0.1 \mathrm{M}, \mathrm{pH}$ 7.4). The micellar solution was introduced into a dialysis membrane bag $(\mathrm{MWCO}=3500)$, and the bag was placed in $50 \mathrm{ml}$ of PBS release media. The media were shaken ( 30 r.p.m.) at $37^{\circ} \mathrm{C}$. At predetermined intervals, $3 \mathrm{ml}$ aliquots of the aqueous solution were withdrawn from the release media, and the same volume of fresh buffer solution was added. The released IMC concentration was determined using a UV-vis spectrophotometer at a wavelength of $320 \mathrm{~nm}$. The rate of controlled drug release was measured by considering the accumulatively released weight of IMC according to the calibration curve for IMC

\section{Cell culture}

HeLa cells were cultured in DMEM/F12 1:1 medium containing 5\% FBS and $1 \%$ antibiotic-antimycotic at $37^{\circ} \mathrm{C}$ in a humidified atmosphere with $5 \% \mathrm{CO}_{2}$.

\section{Cellular viability determination}

The Promega CellTiter 96 AQueuous One Solution kit was used to determine cellular viability. The assay was performed according to the manufacturer's instructions with slight modifications. Briefly, HeLa cells were seeded in a 24 -well plate $\left(3 \times 10^{4} /\right.$ well $)$ overnight and then treated with various concentrations of polymers or a DMSO vehicle added to DMEM/F12 1:1 medium with $1 \% \mathrm{FBS}$ in a humidified $37^{\circ} \mathrm{C}$ incubator supplied with $5 \% \mathrm{CO}_{2}$. After $48 \mathrm{~h}$, the medium in each well was removed and replaced with $400 \mu \mathrm{l}$ of warm PBS and $40 \mu \mathrm{l}$ of CellTiter 96 AQueuous One Solution. The mixture was then incubated at $37^{\circ} \mathrm{C}$ for $1 \mathrm{~h}$. After incubation, $110 \mu \mathrm{l}$ of supernatant from each well was moved to a 96-well plate, and the absorbance at $485 \mathrm{~nm}$ was measured using an enzyme-linked immunosorbent assay reader (Hidex, Turku, Finland).

Table 2 Properties of nucleobase-terminated PNZHpr $_{n}$ micelles

Micelle size $(n m)$

Drug-loading content ${ }^{\mathrm{a}}, \quad$ Drug-entrapment efficiency ${ }^{2}$,

\begin{tabular}{|c|c|c|c|c|c|c|c|c|}
\hline Polymer & $C M C\left(m g l^{-1}\right)$ & (\%) IMC/DOX & (\%) IMC/DOX & Blank & PDI & With IMC & PDI & Zeta potential (mv) \\
\hline Ura-PNZHpr 6 & 16.90 & 12.2 & 24.3 & $82.3 \pm 32.9$ & 0.32 & $97.2 \pm 47.9$ & 0.20 & -13.7 \\
\hline Ade-PNZHpr 6 & 12.05 & 22.7 & 45.4 & $84.3 \pm 22.9$ & 0.18 & $122.9 \pm 69.3$ & 0.33 & -12.8 \\
\hline Thy-PNZHpr 6 & 9.95 & 23.8 & 50.5 & $86.9 \pm 24.5$ & 0.26 & $123.7 \pm 59.6$ & 0.17 & -5.6 \\
\hline Ura-PNZHpr 12 & 5.90 & $39.4 / 24.7$ & $78.8 / 49.4$ & $82.7 \pm 23.4$ & 0.29 & $105.0 \pm 22.4$ & 0.17 & -12.2 \\
\hline Ade-PNZHpr 12 & 4.97 & $44.8 / 18.2$ & $89.6 / 36.4$ & $106.2 \pm 26.4$ & 0.16 & $120.4 \pm 20.1$ & 0.41 & -21.7 \\
\hline Thy-PNZHpr $_{12}$ & 1.51 & $42.4 / 13.2$ & $84.7 / 26.3$ & $67.8 \pm 13.4$ & 0.15 & $134.4 \pm 88.9$ & 0.30 & \\
\hline
\end{tabular}

Abbreviations: Ade, adenine; CMC, critical micelle concentration; DOX, doxorubicin; IMC, indomethacine; PDI, polydispersity index; PNZHpr, polymerization of $\mathrm{N}$-benzyloxycarbonyl-4-hydroxyl-Lproline; Thy, thymine; Ura, uracil.

${ }^{a}$ The molar ratio of drug/polymer $=1 / 1$ 

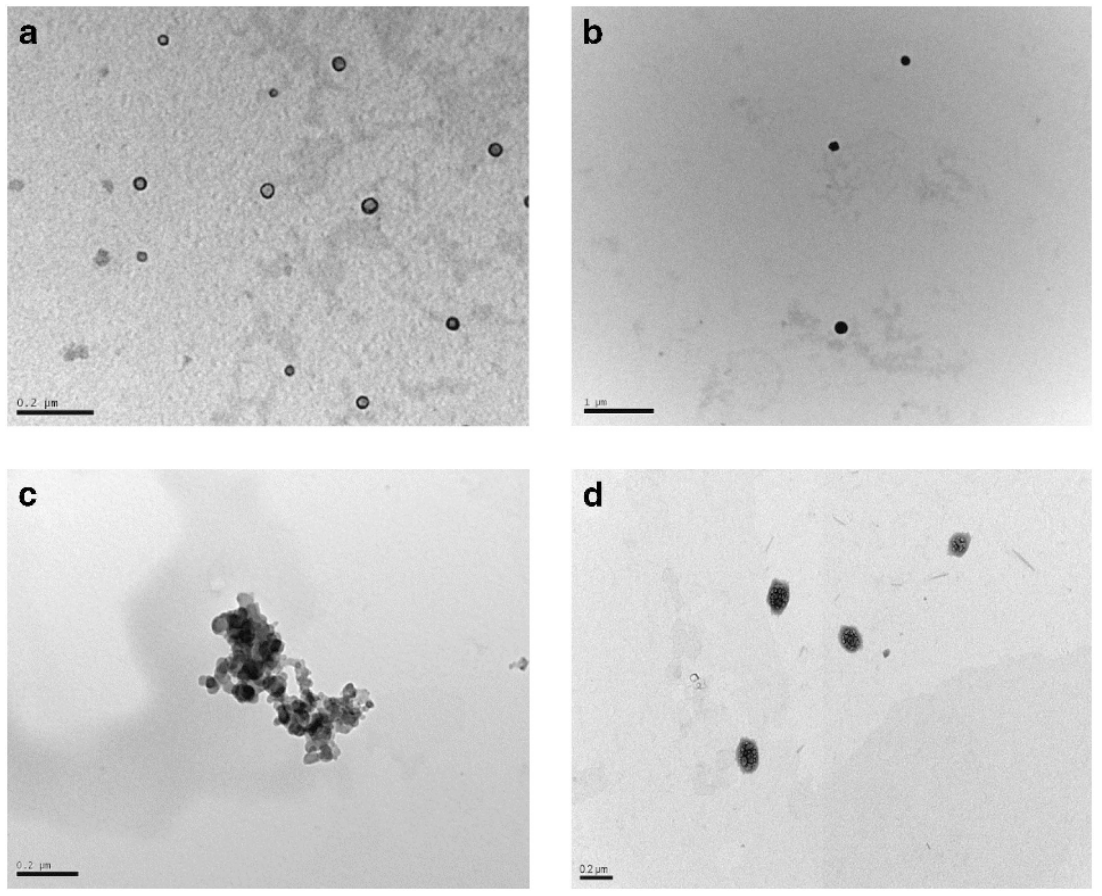

Figure 7 TEM photograph of the micelles formed by (a) Ura-PNZHpr 12 , (d) Ura-PNZHpr 12 mixed with drug.

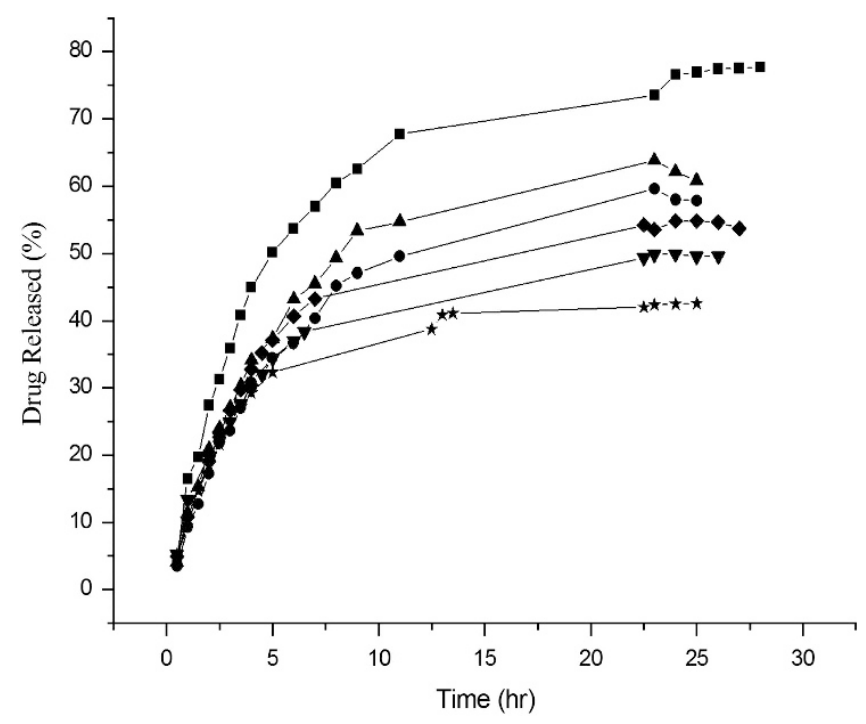

Figure $8 \mathrm{IMC}$ released from the micelles of Ura-PNZHpr $12(\boldsymbol{\nabla})$,

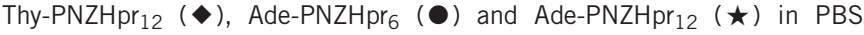
$\left(0.1 \mathrm{M}, \mathrm{pH}\right.$ 7.4) solution at $37^{\circ} \mathrm{C}$ and $\operatorname{Ura}^{-P_{N Z H p r}}{ }_{12}(\boldsymbol{\Lambda})$ and Thy$\mathrm{PNZHpr}_{12}(\mathbf{\square})$ in PBS $(0.1 \mathrm{M}, \mathrm{pH} 5.0)$ at $37^{\circ} \mathrm{C}$.

Uptake of DOX-loaded nucleobase-PNZHpr ${ }_{n}$ micelles by

\section{HeLa cells}

Cellular uptake of nucleobase-PNZHpr ${ }_{n}$ micellar drugs and free drugs was first observed using a fluorescent microscope (IX71, Olympus, Tokyo, Japan). HeLa cells were seeded into a $3.5-\mathrm{mm}$ dish at a cell density of $10^{5} \mathrm{cells} \mathrm{ml}^{-1}$ and incubated overnight. Ura-PNZHpr 12 micellar drugs or free drugs at the same concentration (DOX: $5 \mu \mathrm{g} \mathrm{ml}^{-1}$ ) were then added to DMEM/F12 1:1 medium with $1 \%$ FBS. Cellular uptake of the micellar or free drugs over time was observed based on red fluorescence. The results were quantified using the Image (NIH, Bethesda, MD, USA). (b) Ade-PNZHpr 12 , (c) Ura-PNZHpr 12 mixed with Ade-PNZHpr 12 and

\section{RESULTS AND DISCUSSION}

Synthesis and characterization of nucleobase-modified poly(pseudo-amino acid) amphiphilic polymers

As illustrated in Scheme 1, the strategy for synthesizing nucleobasemodified poly(pseudo-amino acid) amphiphilic polymers was based on a click reaction between a $N$-(2-propynyl)-nucleobase derivative and $\mathrm{PNZHpr}_{\mathrm{n}}$ end-capped with an azide. The $\mathrm{N}$-(2-propynyl)-nucleobase derivatives were synthesized by propynylation of the nucleobases, in the presence of potassium carbonate or sodium hydride as a base. ${ }^{11}$ Azideterminated $\mathrm{PNZHpr}_{\mathrm{n}}$ was prepared by the homopolycondensation of $\mathrm{NZHpr}$ and the initiator 2-(2-chloroethoxy)ethanol (molar ratio: $10 / 1$ or 20/1) in the presence of $\operatorname{SnOct}_{2}$ (3 wt\%) as a catalyst in bulk at $140{ }^{\circ} \mathrm{C}$ for $48 \mathrm{~h}$. The primary hydroxyl group of 2-(2chloroethoxy)ethanol was more reactive than the secondary hydroxyl group of NZHpr during polymerization. The prepared $\mathrm{Cl}\left(\mathrm{CH}_{2} \mathrm{CH}_{2} \mathrm{O}\right)_{2}-$ PNZHpr $_{n}$ was characterized by GPC $\left(\right.$ PNZHpr $_{6}: M_{\mathrm{n}}=1480, M_{\mathrm{w}} /$ $\left.M_{\mathrm{n}}=1.23 ; \mathrm{PNZHpr}_{12}: M_{\mathrm{n}}=2880, M_{\mathrm{w}} / M_{\mathrm{n}}=1.68\right)$ and ${ }^{1} \mathrm{H} \quad \mathrm{NMR}$ spectroscopy. Polymerization conversion of the monomers was lower than that of the corresponding feeds. The characteristic signals of the main chain of $\mathrm{PNZHpr}_{\mathrm{n}}$ were observed at $\delta=1.99-2.42$ p.p.m. $\left(\mathrm{H}_{\mathrm{e}}, \mathrm{C}_{3}\right.$ methylene protons), 3.50-3.84 p.p.m. ( $\mathrm{H}_{\mathfrak{c}}, \mathrm{C}_{5}$ methylene protons), 4.22 4.51 p.p.m. ( $\mathrm{H}_{\mathrm{f}}, \mathrm{C}_{2}$ methine proton), 5.05-5.21 p.p.m. ( $\mathrm{H}_{\mathrm{b}}$, benzylic protons of the protecting group), 5.35 p.p.m. $\left(\mathrm{H}_{\mathrm{d}}, \mathrm{C}_{4}\right.$ methine proton) and 7.30 p.p.m. ( $\mathrm{H}_{\mathrm{a}}$, phenyl proton of the protecting group), as reported for linear poly $(N-\mathrm{CBz}-\mathrm{Hpr})_{\mathrm{n}}{ }^{21}$ The signal of $\mathrm{H}_{\mathrm{b}}$ was observed as a double rather than a singlet, possibly due to the effect of the chirality of proline. The same phenomenon was reported by Park and colleagues ${ }^{24}$ and Putnam and Langer ${ }^{25}$ Several additional, and relatively overlapping peaks resulting from the incorporation of 2-(2-chloroethoxy)ethanol were observed at 3.49-3.88 p.p.m. and 4.25-4.52 p.p.m.

According to Scheme 1, the terminal chloride of $\mathrm{Cl}\left(\mathrm{CH}_{2} \mathrm{CH}_{2} \mathrm{O}\right)_{2}-$ $\mathrm{PNZHpr}_{\mathrm{n}}$ must be converted into an azide by reaction with sodium azide. Thus we mixed $\mathrm{Cl}\left(\mathrm{CH}_{2} \mathrm{CH}_{2} \mathrm{O}\right)_{2}-\mathrm{PNZHpr}_{n}$ with an equal portion of sodium azide in DMF and maintained the solution at 

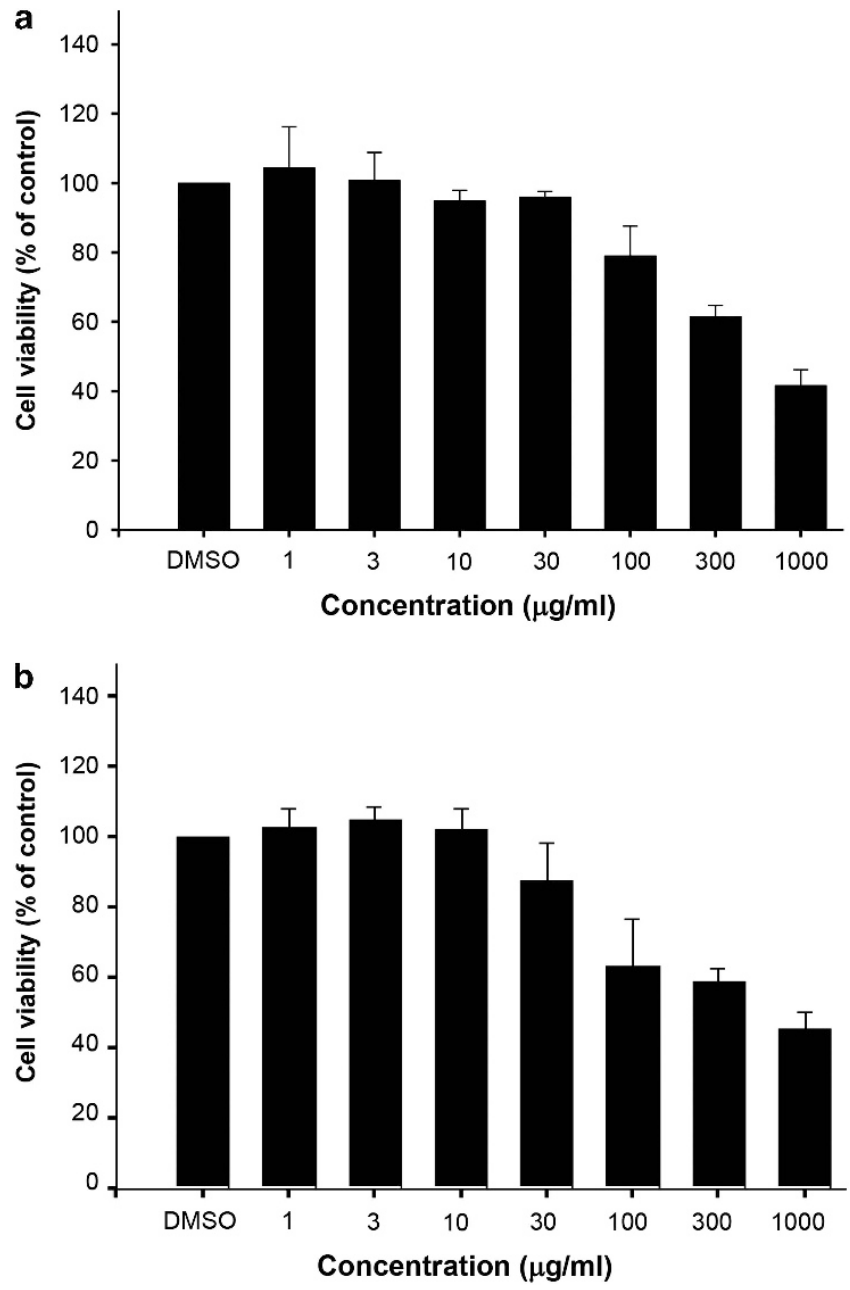

Figure 9 Viability of HeLa cells at various Ade-PNZHpr 12 (a) and Ura$\mathrm{PNZHpr}_{12}$ (b) concentrations. Data are show as the mean \pm s.e. $(n=3)$.

room temperature overnight. The results of the substitution were observed, and as expected, the IR spectrum revealed a new absorption band at $2025 \mathrm{~cm}^{-1}$, which is characteristic of azides (Figure $2 \mathrm{~b}$ ). A representative ${ }^{1} \mathrm{H}$ NMR spectrum of $\mathrm{N}_{3}\left(\mathrm{CH}_{2} \mathrm{CH}_{2} \mathrm{O}\right)_{2}-\mathrm{PNZHpr}_{12}$ is shown in Figure 1a. The resonance peaks were assigned to the corresponding hydrogen atoms of the polymers.

According to Haddleton and colleagues $^{26}$ and Lee et al., ${ }^{27}$ postpolymerization modification via $\mathrm{Cu}(\mathrm{I})$-catalyzed click chemistry has been applied to the synthesis of nucleobase-polymers. This method is highly efficient and depend on the click reaction between the alkynyl side chain of nucleobases to $\mathrm{N}_{3}\left(\mathrm{CH}_{2} \mathrm{CH}_{2} \mathrm{O}\right)_{2}$ - $\mathrm{PNZHpr}$. In the current study, the click reaction of the synthetic azideterminated $\mathrm{N}_{3}\left(\mathrm{CH}_{2} \mathrm{CH}_{2} \mathrm{O}\right)_{2}$ - $\mathrm{PNZHpr}_{\mathrm{n}}$ and alkynyl nucleobase was conducted in DMF at $60^{\circ} \mathrm{C}$ for $72 \mathrm{~h}$, in the presence of CuI and $\mathrm{Et}_{3} \mathrm{~N}$. The alkynyl groups were almost completely converted into 1,2,3triazoles (that is, successful click conjugation of the nucleobase moieties), according to FT-IR characterization. Figures $2 \mathrm{a}$ and $\mathrm{b}$ show the disappearance of the characteristic absorbances of the $\mathrm{C} \equiv \mathrm{C}$ and azide moieties at $2106 \mathrm{~cm}^{-1}$ and $2025 \mathrm{~cm}^{-1}$, respectively. The ${ }^{1} \mathrm{H}$ NMR spectrum (Figure 1b) revealed new signals from the nucleobase. In addition, characteristic signals at 7.69 and 5.60 p.p.m. were attributed to the vinylic proton resonances of the uracil ring in the Ura-PNZHpr 12 . Therefore the results from both FT-IR and ${ }^{1} \mathrm{H}$
NMR confirmed that the effective clicking of nucleobase produced nucleobase-PNZHpr 6 . Figure 3 shows the representative GPC curves of Ura-PNZHpr 12 compared with those of the original $\mathrm{N}_{3}\left(\mathrm{CH}_{2} \mathrm{CH}_{2} \mathrm{O}\right)_{2}-\mathrm{PNZHpr}_{12}$. The GPC traces show a unimodal distribution of the Ura-PNZHpr 12 , with a slight shift in the peak toward the higher molecular weight region, compared with the peak of the original $\mathrm{N}_{3}\left(\mathrm{CH}_{2} \mathrm{CH}_{2} \mathrm{O}\right)_{2}-\mathrm{PNZHpr}_{12}$. The results of nucleobase coupling to $\mathrm{PNZHpr}_{\mathrm{n}}$ are shown in Table 1. The yields, which were between $55 \%$ and $80 \%$, were moderate to high. There was good agreement between the theoretical number-average molecular weight $\left(M_{\mathrm{n}, \mathrm{th}}\right)$ and the number-average molecular weight determined by ${ }^{1} \mathrm{H}$ $\operatorname{NMR}\left(M_{\mathrm{n}, \mathrm{NMR}}\right)$. However, the $M_{\mathrm{n}, \mathrm{GPC}}$ was less than the $M_{\mathrm{n}, \text { th }}$ and $M_{\mathrm{n}, \mathrm{NMR}}$ due to the more compact structure compared with the linear standards used to calibrate the GPC.

\section{Assembly of nucleobase-terminated polymers}

Base-pair interaction between adenine and thymine or uracil often involve both $\pi-\pi$ and hydrogen-bonding interactions. According to the literature, these interactions can cause distinct changes in the UV-vis spectra of nucleobase-functionalized materials. ${ }^{10}$ Therefore, we examined the temperature dependence of aggregate formation by the nucleobase-terminated polymers in water by measuring UV-vis spectra at temperatures increasing from 20 to $90{ }^{\circ} \mathrm{C}$ (heating rate: $\left.1{ }^{\circ} \mathrm{C} \min ^{-1}\right)$. Sharp increases were observed in the absorption band of Ura-PNZHpr 12 at $263 \mathrm{~nm}$ and the absorption band of Thy-PNZHpr 12 at $267 \mathrm{~nm}$ at thermal denaturation temperatures of approximately 80 and $60{ }^{\circ} \mathrm{C}$, respectively (Figure 4). These observations were indicative of thermally induced dissociation of nucleobase-terminated polymer aggregates in water resulting from reduced $\mathrm{H}$-bonding interactions between the polymer chains. By contrast, the UV-vis absorption band of Ade-PNZHpr 12 decreased at $264 \mathrm{~nm}$ during heating at a thermal denaturation temperature of $48{ }^{\circ} \mathrm{C}$ (Figures $4 \mathrm{c}$ and $\mathrm{d}$ ), indicating that adenine units may cooperatively participate in this transition. However, the exact nature of this observation remains unclear, and additional studies are necessary to interpret this observation accurately.

\section{Molecular recognition properties}

The molecular recognition behavior of nucleobase-terminated polymers with complementary small molecules in water was examined by fluorescence measurements. The emission spectra were obtained by excitation at $436 \mathrm{~nm}$ and are shown in Figure 5. Adenosine, which is complementary to the thymine units of Thy-PNZHpr 12 for DNA, and the uracil units of Ura-PNZHpr 12 for RNA was used. Adding this molecule (equimolar or in a 10 -fold ratio to the nucleobase units of the polymers) to a nucleobase-terminated polymer $\left(10^{-4} \mathrm{M}\right)$ in water caused a substantial increase (approximately 2-4-fold) in the fluorescence intensity and a slight red-shift (Figures $5 \mathrm{a}$ and $\mathrm{b}$ ). In a control experiment, adding adenosine to a non-complementary AdePNZHpr $_{12}$ caused little change (1.08-fold) in fluorescence (Figure $5 \mathrm{c}$ ). These results suggested that nucleobase-terminated $\mathrm{PNZHpr}_{\mathrm{n}}$ could undergo selective $\mathrm{H}$-bonding-based molecular recognition of complementary guest molecules in water. This association likely reduced the quenching effect of free adenosine units, potentially by causing reorientation during hydrogen bonding and decreasing the degree of $\pi$-stacking between adenosine units. Both effects could cause an increase in fluorescence intensity. The emission intensities of the Ura-PNZHpr ${ }_{n}$ and Thy-PNZHpr ${ }_{n}$ treated with a 10-fold molar ratio of adenosine were considerably higher than those treated with an equimolar ratio of adenosine. This difference was likely due to an increased aggregation at this high adenosinely concentration, 

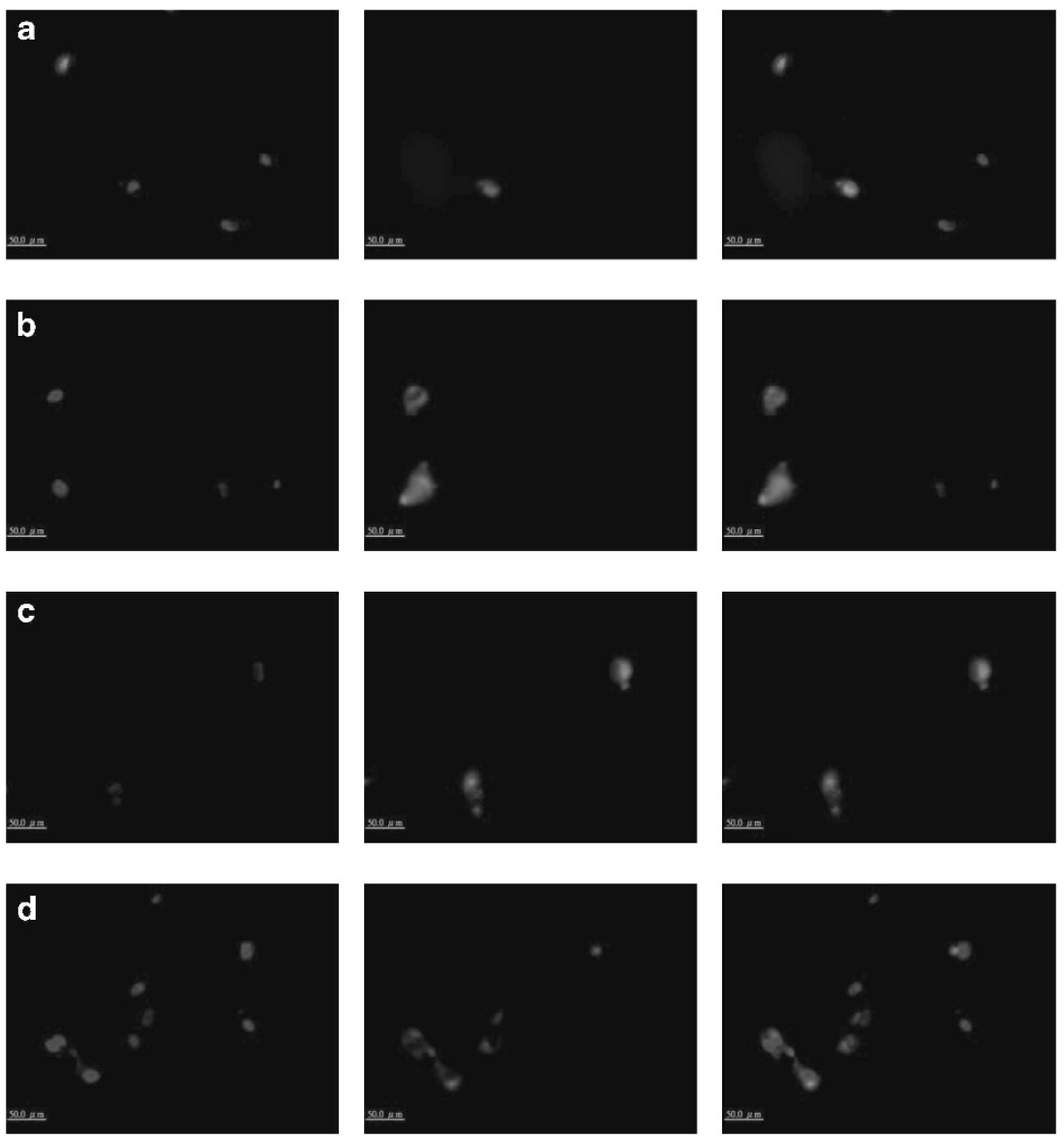

Figure 10 Fluorescent microscopic images of HeLa cells incubated with free DOX (a, b) and with DOX-loaded Ade-PNZHpr 12 micelles (c, d) for 5 min (a, c) and $1 \mathrm{~h} \mathrm{(b,} \mathrm{d).} \mathrm{For} \mathrm{each} \mathrm{row,} \mathrm{the} \mathrm{panels} \mathrm{from} \mathrm{left} \mathrm{to} \mathrm{right} \mathrm{show} \mathrm{the} \mathrm{cells} \mathrm{with} \mathrm{Hoechst} 33342$ nuclear staining, DOX fluorescence and the merged image (scale bar: $50 \mu \mathrm{m}$; brightness is not proportional to fluorescence intensity). A full color version of this figure is available at the Polymer Journal online.

indicating that competitive hydrogen-bonding with complementary molecules in water reduces binding between adenosine and the polymer base units with equimolar adenosine. ${ }^{10}$

\section{Micelles of nucleobase-PNZHpr}

The amphiphilic nature of the nucleobase-PNZHpr ${ }_{\mathrm{n}}$ polymers, which consists of a hydrophilic nucleobase and hydrophobic PNZHpr segment, enables micelles to form in water. The characteristics of the nucleobase-PNZHpr ${ }_{n}$ micelles in an aqueous phase were investigated using fluorescence techniques. CMCs of the nucleobase-PNZHpr $r_{n}$ in an aqueous phase were determined using pyrene as a probe molecule. The fluorescence intensity of the excitation spectrum of pyrene (data not shown) was observed to increase as the nucleobase-PNZHpr $\mathrm{n}_{\mathrm{n}}$ polymer concentration increased. The characteristic feature of the pyrene excitation spectrum, namely a red-shift of the $(0,0)$ band from 334 to $338 \mathrm{~nm}$ during partitioning into a micellar hydrophobic core, was used to determine the CMC values of nucleobase-PNZHpr ${ }_{n}$ polymers. Figure 6 shows the intensity ratios $\left(I_{338} / I_{334}\right)$ of pyrene excitation spectra versus the logarithm of nucleobase-PNZHpr ${ }_{n}$ polymer concentrations. The CMC was determined based on the intersection of straight line segments, drawn through the points of the lowest polymer concentrations, which lie on a nearly horizontal line, and the points of the rapidly rising region of the plot. Table 2 lists the $\mathrm{CMC}$ values of the nucleobase-PNZHpr $r_{n}$ polymers that were determined for the different compositions. The nucleobase-terminated $\mathrm{PNZHpr}_{\mathrm{n}}$ polymers formed micelles in the aqueous phase. The CMCs ranged from 1.51 to $16.90 \mathrm{mgl}^{-1}$. The nucleobase-PNZHpr ${ }_{\mathrm{n}}$ polymers exhibited lower CMC values than those of the surfactant, clearly indicating that nucleobase-PNZHpr ${ }_{n}$ yielded thermodynamically favorable selfassociation. The CMC values of the micelles decreased as the length of the hydrophobic segment increased.

The mean hydrodynamic diameters of micelles incorporating IMC and blank micelles measured by DLS ranged from 97 to $135 \mathrm{~nm}$ and from 68 to $106 \mathrm{~nm}$, respectively. The size of the micelles incorporating IMC was larger than that of the blank micelles, because the hydrophobic drug was incorporated, but the size still remained below $200 \mathrm{~nm}$ for all formations. Small particle sizes $(<200 \mathrm{~nm})$ can reduce the level of uptake in the reticulate endothelial system, minimize renal excretion and strengthen the accumulation of micelle-encapsulated drugs within tumors by the enhanced permeability and retention effect. $^{28}$ Figure 7 shows the morphology of nucleobase-PNZHpr 12 micelles. Different morphologies were observed for nucleobase$\mathrm{PNZHpr}_{\mathrm{n}}$. Regarding Ura-PNZHpr ${ }_{12}$, a vesicular micellar structure was formed by blank and IMC-loaded micelle (Figures $7 \mathrm{a}$ and $\mathrm{d}$ ). Ade-PNZHpr 12 formed a spherical micellar structure (Figure 7b). After Ura- and Ade- $\mathrm{PNZHpr}_{12}$ were mixed at an equimolar ratio, an aggregate morphology was observed (Figure 7c). Several factors affect the morphologies of amphiphilic copolymer assemblies in an aqueous solution, such as polymer composition, the degree of H-bonding interactions when using a nucleobase unit with water and core-shell interfacial energy. 

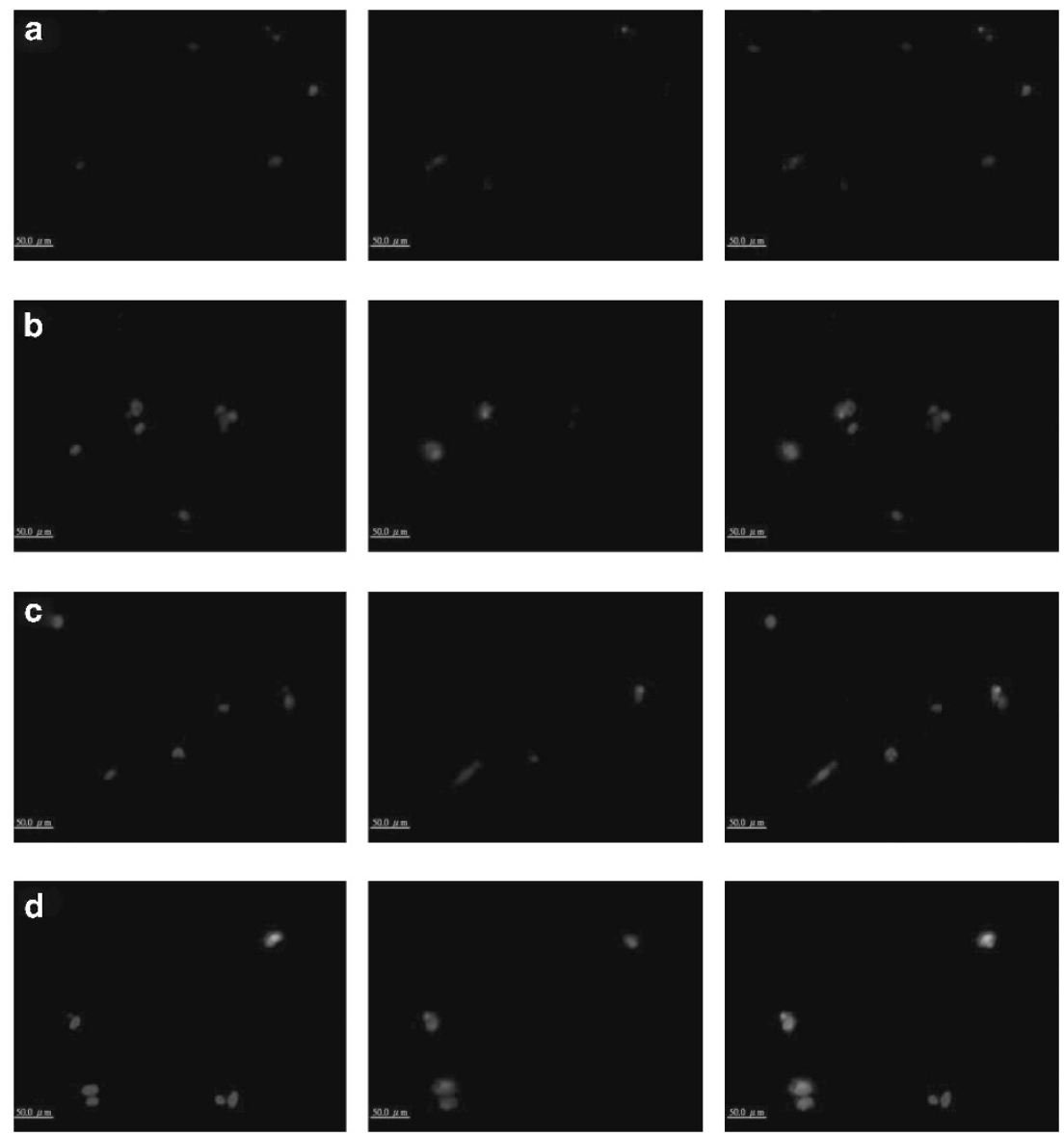

Figure 11 Fluorescent microscopic images of HeLa cells incubated with free DOX (a, b) and with DOX-loaded Ura-PNZHpr 12 micelles (c, d) for 5 min (a, $\mathbf{c}$ ) and $1 \mathrm{~h}(\mathbf{b}, \mathbf{d})$. For each row, the panels from left to right show the cells with Hoechst 33342 nuclear staining, DOX fluorescence and the merged image (scale bar: $50 \mu \mathrm{m}$; brightness is not proportional to fluorescence intensity). A full color version of this figure is available at the Polymer Journal online.

Evaluation drug-loading content, drug-entrapment efficiency for IMC and DOX and in vitro release of IMC

This study determined the drug-loading content and drugentrapment efficiency of the polymeric micelles by UV-vis absorption spectroscopy. IMC showed a maximum absorption peak that was proportional to concentration at $320 \mathrm{~nm}$. After releasing IMC and removing the polymer precipitate, the amount of loaded IMC was determined from the absorbance at $320 \mathrm{~nm}$. Table 2 lists the calculated drug-loading content and entrapment efficiency values. At a constant feed weight ratio (1:1), the entrapment efficiency and drug-loading content increased to $89.6 \%$ and $44.8 \%$, respectively, as the length of the hydrophobic segment increased. During drug loading, the nucleobase-PNZHpr ${ }_{n}$ polymers demonstrated excellent drug-carrier characteristics based on their high drug-loading efficiency and significant drug-content capacity.

DOX is a DNA-interacting drug widely used in chemotherapy. DOX was also used as a model anticancer drug to test the loading and entrapment efficiency of the nucleobase-PNZHpr 12 micelles. The nucleobase-PNZHpr 12 micelles were loaded with DOX $(1: 1 \mathrm{w} / \mathrm{w})$ in an aqueous solution at room temperature, resulting in DOX-loading contents and encapsulation efficiencies in the range of $13.2-24.7 \%$ and $26.3-49.4 \%$, respectively, as shown in Table 2 . The high drugloading capacity resulted from electrostatic forces and hydrogenbonding interactions between DOX and the polymers.

The anti-inflammatory drug IMC was used as a model drug to investigate the controlled release properties of the nucleobase-
PNZHpr $_{n}$ polymers in vitro. Release rates were monitored by determining the cumulative concentration of the released drug. Figure 8 shows the release profiles of IMC from micelles of Ade-PNZHpr 6 , Ade-PNZHpr 12 , Thy-PNZHpr 12 and Ura-PNZHpr 12 under stimulated physiological conditions (PBS, pH 7.4). The release percentage of IMC from the nucleobase-PNZHpr ${ }_{n}$ micelles followed the order Thy-PNZHpr ${ }_{12}>$ Ura-PNZHpr ${ }_{12}>$ Ade-PNZHpr 12 . This trend is attributed to the hydrophilicity of nucleobase Thy being greater than that of Ura and Ade. The release rate of Ade-PNZHpr 6 was substantially higher than that of Thy-PNZHpr 12 and Ura$\mathrm{PNZHpr}_{12}$. The accelerated release can be ascribed to the high hydrophilicity of the Ade- $\mathrm{PNZHpr}_{6}$ micelles caused by its low molecular weight, which could facilitate penetration by water and promote polymer matrix erosion. The accumulative release of IMC was approximately $50 \%$ within $24 \mathrm{~h}$ without an apparent initial burst release, which is a crucial criterion for a micellar drug delivery system to be applicable in vivo. In addition, the drug release behavior of the IMC-loaded nucleobase-PNZHpr ${ }_{12}$ micelles was examined at $\mathrm{pH} 5.0$ to stimulate the endosomal environment. The cumulative release of IMC within $24 \mathrm{~h}$ was higher at $\mathrm{pH} 5.0$ than at 7.4. The rapid release of IMC from the IMC-loaded micelles in an acidic environment is likely due to the protonation of the amino group of the nucleobase and the shedding of the micelle shell via the hydrolysis of the polymer ester backbond under acidic conditions. Accelerated drug release at a low $\mathrm{pH}$ is particularly compelling for achieving tumor-targeted delivery with micelles because the $\mathrm{pH}$ value at solid tumor has been reported 

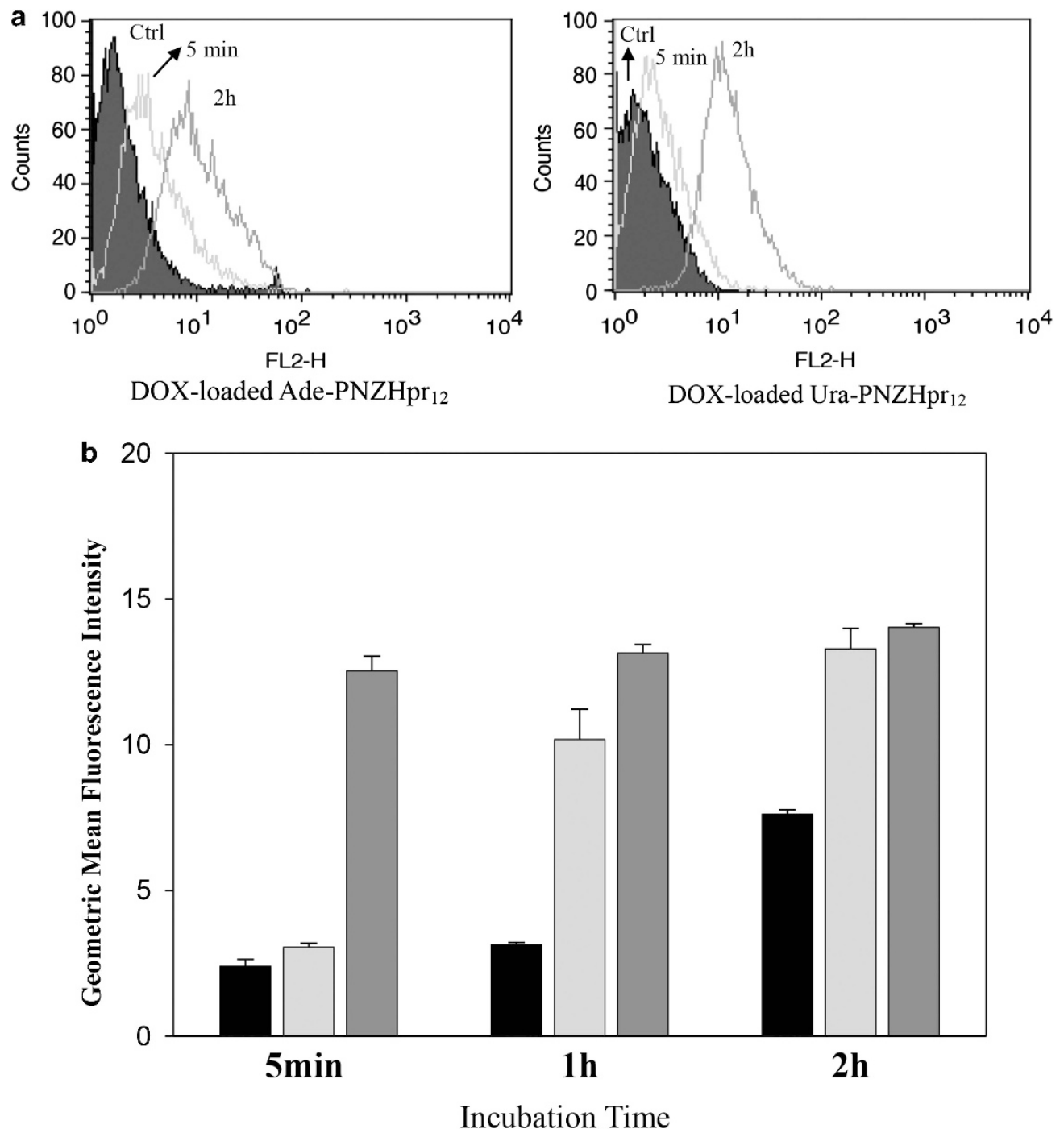

Figure 12 Flow cytometric histogram profiles of HeLa cells treated with DOX-loaded Ade-PNZHpr 12 micelles (a, left) and Ura-PNZHpr 12 (a, right) for 5 min and $2 \mathrm{~h}$. Control groups were cells that did not receive any treatment, representing basal fluorescent levels. (b) Geometric mean fluorescence intensities of free DOX (black), DOX-loaded Ura-PNZHpr 12 (light gray) and DOX-loaded Ade-PNZHpr 12 (gray). Data are shown as the mean \pm s.e. ( $n=3$ ). A full color version of this figure is available at the Polymer Journal online.

to be one order of magnitude lower compared with normal physiological conditions.

\section{Cell viability study}

We used the MTS assay and HeLa cancer cells to quantify the in vitro cytotoxicities of the nucleobase-PNZHpr 12 polymer at various concentrations. Wells containing only a DMSO vehicle without polymers were treated as positive controls and were designated as 100\% viable cells. The equation $[\mathrm{Abs}]_{\text {sample }} /[\mathrm{Abs}]_{\text {control }} \times 100$ was used to calculated relative cell viability. Figure 9 shows a comparison of the cell viability of HeLa cells after $48 \mathrm{~h}$ of incubation with various concentrations of Ade-PNZHpr 12 and Ura-PNZHpr ${ }_{12}$. The results indicated low cytotoxicity against HeLa cells, even when the polymer concentration was $100 \mu \mathrm{g} \mathrm{ml}^{-1}$, as well as cell survival of $80 \%$.

In vitro cellular uptake and distribution of DOX-loaded micelles Because DOX emits fluorescence at $595 \mathrm{~nm}$ when excited at $532 \mathrm{~nm}$, the cellular uptake and intracellular distribution of free DOX and DOX-loaded micelles can easily be monitored. Free DOX and DOX- loaded micelles prepared using Ade-PNZHpr 12 and Ura-PNZHpr 12 were incubated with HeLa cells and then observed using fluorescence microscopy at $5 \mathrm{~min}$ and at $1 \mathrm{~h}$ posttreatment. In the images, the red regions indicated DOX molecules, whereas the blue regions correspond to nuclei stained with Hoechst dye. As shown in Figures 10 and 11 , after $1 \mathrm{~h}$ of incubation with free DOX, strong fluorescence was observed primarily in one condensed area of the cells, presumably the nuclei. This result was consistent with previous findings, indicating that DOX molecules can enter cells and accumulate rapidly in their nuclei. By contrast, in cells incubated with DOX-loaded micelles, fluorescence was observed primarily in the cytoplasm, and weaker fluorescence was observed in the nucleus. For DOX-loaded micelles, the red fluorescence in both the cytoplasm and nuclei increased over time, most likely because of the diffusion of released DOX from the micelles into the nuclei. These results suggested that DOX-loaded micelles may be internalized by an endocytic mechanism, followed by the release and diffusion of DOX molecules from endosomal compartments to eventually accumulate in the nucleus, as reported by other investigators. ${ }^{29,30}$ 
Flow cytometric quantification of internalized DOX-loaded micelles

To evaluate the quantity and kinetics of cellular entry by Ade-PNZHpr 12 and Ura-PNZHpr 12 -encapsulated DOX, we incubated HeLa cells $\left(1.5 \times 10^{5} /\right.$ dish $)$ with free DOX and DOX-loaded Ade-PNZHpr ${ }_{12}$ or Ura-PNZHpr 12 in DMEM $+1 \%$ FBS for $5 \mathrm{~min}$, $1 \mathrm{~h}$ and $2 \mathrm{~h}$ before fixation. The samples were then analyzed by flow cytometry. The emitted intracellular DOX fluorescence was recorded using an FL2-H channel and quantified as the geometric means. The fluorescence intensity of DOX increased over time, whereas the intracellular fluorescence after treatment with DOX-loaded Ade-PNZHpr 12 micelles was near-maximum within $5 \mathrm{~min}$ and remained relatively constant at the $2 \mathrm{~h}$ time point (Figure 12a). However, within the first $5 \mathrm{~min}$, the intracellular fluorescence resulting from the DOX-loaded Ura-PNZHpr 12 micelles was significantly lower than that from the DOX-loaded Ade-PNZHpr ${ }_{12}$ micelles. This decreased cellular uptake may be due to the higher solubility of Ade-PNZHpr ${ }_{12}$ compared with Ura-PNZHpr 12 . Quantitative data revealed that the increase in intracellular free DOX was both slow and time dependent, and the geometric mean fluorescence intensities increased from 2.5 at $5 \mathrm{~min}$ to 8.0 at $2 \mathrm{~h}$. By contrast, the fluorescence intensities of HeLa cells incubated with DOX-loaded Ade-PNZHpr ${ }_{12}$ micelles were 12.5 at $5 \mathrm{~min}$ and 14.5 at $2 \mathrm{~h}$ (Figure 12b). These results indicated faster internalization of DOX-loaded nucleobase-PNZHpr compared with free DOX inside by the HeLa cells.

\section{CONCLUSIONS}

A novel amphiphilic nucleobase end-capped poly(pseudo-amino acid) was synthesized via the Huisgen $[3+2]$ cycloaddition of an alkynyl-functionalized nucleobase with the azido-end group of $\mathrm{PNZHpr}_{\mathrm{n}}$. The formation of micelles by these amphiphilic polymers was confirmed using a fluorescence probe technique and DLS. An increase in the length of the hydrophobic segment led to lower CMC values. Different morphologies of the assemblies were observed by changing the nucleobase coupling to the polymer. The nucleobase$\mathrm{PNZHpr}_{\mathrm{n}}$ selectively bound to small complementary molecules. These micelles were observed to release drug rapidly in an acidic environment. DOX-loaded micelles were more efficiently internalized than free DOX by HeLa cells.

\section{ACKNOWLEDGEMENTS}

This research was supported by Grants from the National Science Council (NSC 101-2221-E-182-009) and Chang Gung Memorial Hospital (CMRPD5B0012).

1 Wang, D., Chen, H., Su, Y., Qiu, F., Zhu, L., Huan, X., Zhu, B., Yan, D., Guo, F. \& Zhu, X. Supramolecular amphiphilic multiarm hyperbranched copolymer: synthesis, self-assembly and drug delivery applications. Polym. Chem. 4, 85-94 (2013).

2 Vashist, A., Vashist, A., Gupta, Y. K. \& Ahmad, S. Recent advances in hydrogel based drug delivery systems for the human body. J. Mater. Chem. 2, 147-166 (2014).

3 Chen, S., Zhang, X. Z., Cheng, S. X., Zhuo, R. X. \& Gu, Z. W. Functionalized amphiphilic hyperbranched polymers for targeted drug delivery. Biomacromolecules $\mathbf{9}$, 2578-2585 (2008).

4 Mikhail, A. S. \& Allen, C. Block copolymer micelles for delivery of cancer therapy: transport at the whole body, tissue and cellular levels. J. Control. Release 138, 214-223 (2009).

5 Tyrrell, Z. L., Shen, Y. Q. \& Radosz, M. Fabrication of micellar nanoparticles for drug delivery through the self-assembly of block copolymers. Prog. Polym. Sci. 35, 1128-1143 (2010).
6 Miyata, K., Christie, R. J. \& Kataoka, K. Polymeric micelles for nano-scale drug delivery. React. Funct. Polym. 71, 227-234 (2011)

7 Chiu, F. C., Wang, S. W., Peng, K. Y. \& Lee, R. S. Synthesis and characterization of amphiphilic PLA-(P $\left.\alpha \mathrm{N}_{3} \mathrm{CL}-\mathrm{g}-\mathrm{PBA}\right)$ copolymers by ring-opening polymerization and click reaction. Polymer 53, 3476-3484 (2012).

8 McHale, R. \& O'Reilly, P. K. Nucleobase containing synthetic polymers: advancing biomimicry via controlled synthesis and self-assembly. Macromolecules 45, 7665-7675 (2012).

9 Wang, J. H., Altukhov, O., Cheng, C. C., Chang, F. C. \& Kuo, S. W. Supramolecular structures of uracil-functionalized PEG with multi-diamidopyridine poss through complementary hydrogen bonding interactions. Soft Matter 9, 5196-5296 (2013).

10 Lo, P. K. \& Sleiman, H. F. Synthesis and molecular recognition of conjugated polymer with DNA-mimetic properties. Macromolecules 41, 5590-5603 (2008).

11 Kuang, H., Wu, S., Xie, Z., Meng, F., Jing, X. \& Huang, Y. Biodegradable amphiphilic copolymer containing nucleobase: synthesis, self-assembly in aqueous solutions, and potential use in controlled drug delivery. Biomacromolecules 13, 3004-3012 (2012).

12 Ostas, E., Schrőter, K., Beiner, M., Yan, T., Thurn-Albrecht, T. \& Binder, W. H. Poly( $\varepsilon-$ caprolactone)-poly(isobutylene): a crystallizing, hydrogen-bonded pseudo-block copolymer. J. Polym. Sci. Part A Polym. Chem. 49, 3404-3416 (2011).

13 Xiong, X., Wu, C., Zhou, C., Zhu, G., Chen, Z. \& Tan, W. Responsive DNA-based hydrogels and their applications. Macromol. Rapid Commun. 34, 1271-1283 (2013).

14 Bernard, J., Lortie, F. \& Fenet, B. Design of heterocomplementary H-bonding RAFT agents-towards the generation of supramolecular star polymers. Macromol. Rapid Commun. 30, 83-88 (2009).

15 Lin, I. H., Cheng, C. C., Yeh, Y. C. \& Chang, F. C. Synthesis and assembly behavior of heteronucleobase-functionalized poly(E-caprolactone). Macromolecules 43, 1245 1252 (2010).

16 Spijker, H. J., Dirks, A. J. \& Van Hest, J. C. M. Synthesis and assembly behavior nucleobase-functionalized block copolymers. J. Polym. Sci. Part A Polym. Chem. 44, 4242-4250 (2006).

17 Lutz, J. F., Thünemann, A. F. \& Nehring, R. Preparation by controlled radical polymerization and self-assembly via base-recognition of synthetic polymers bearing complementary nucleobases. J. Polym. Sci. Part A Polym. Chem. 43, 4805-4818 (2005).

18 Lee, R. S., Lin, Z. K., Yang, J. M. \& Lin, F. H. Synthesis of glycopoly(pseudo amino acid)s and their interaction with lectins. J. Polym. Sci. Part A Polym. Chem. 44, 4268-4280 (2006).

19 Kataoka, K., Matsumoto, T., Yokoyama, M., Okano, T., Sakural, Y., Fukushima, S., Okamoto, K. \& Kwon, G. S. Doxorubicin-loaded poly(ethylene glycol)-poly( $\beta$-benzyl-Laspartate) copolymer micelles: their pharmaceutical characteristics and biological significance. J. Control. Release 64, 143-153 (2000).

20 Lee, R. S., Li, H. R., Yang, J. M. \& Tsai, J. F. Y. Synthesis of biodegradable poly(trans-4hydroxy-N-benzyloxycarbonyl-L-proline)-block-poly( $\varepsilon$-caprolactone) copolymers and micellar characterization. Polymer 46, 10718-10726 (2005).

21 Wilhelm, M., Zhao, C. L., Wang, Y. \& Winnik, A. Poly(styrene-ethylene oxide) block copolymer micelle formation in water: a fluorescence probe study. Macromolecules $\mathbf{2 4}$, 1033-1040 (1991).

22 Zhang, X., Mei, H., Hu, C., Zhong, Z. \& Zhuo, R. Amphiphilic triblock copolycarbonates with poly(glycerol carbonate) as hydrophilic blocks. Macromolecules 42, 1010-1016 (2009).

23 Provencher, S. W. \& Hendrix, J. Direct determination of molecular weight distribution of polystyrene in cyclohexane with photon correction spectroscopy. J. Chem. Phys. 69, 4271-4276 (1978).

$24 \mathrm{Lim}$, Y. B., Choi, Y. H. \& Park, J. S. A self-destroying polycationic polymer: biodegradable poly(4-hydroxy-L-proline ester). J. Am. Chem. Soc. 121, 5633-5639 (1999).

25 Putnam, D. \& Langer, R. Poly(4-hydroxy-L-proline ester): low-temperature polycondensation and plasmid DNA complexation. Macromolecules 32, 3658-3662 (1999).

26 Geng, J., Mantovani, G., Tao, L., Nicolas, J., Chen, G., Wallis, R., Mitchell, D. A., Johnson Benjamin, R. G., Evans, S. D. \& Haddleton, D. M. A self-destroying polycationic polymer: biodegradable poly(4-hydroxy-L-proline ester). J. Am. Chem. Soc. 129, 15156-15163 (2007).

27 Lee, R. S. \& Huang, Y. T. Synthesis and characterization of amphiphilic block-graft MPEG-b-(P $\alpha \mathrm{N}_{3} \mathrm{CL}$-g-alkyne) degradable copolymers by ring-opening polymerization and click chemistry. J. Polym. Sci. Part A Polym. Chem. 46, 4320-4331 (2008).

28 Prabaharan, M., Grailer, J. J., Pilla, S., Steeber, D. A. \& Gong, S. Q. Amphiphilic multiarm-block copolymer conjugated with doxorubicin via pH-sensitive hydrazone bond for tumor-targeted drug delivery. Biomaterials 30, 5757-5766 (2009).

29 Zhang, W. L., Li, Y. L., Liu, L. X., Sun, Q. Q., Shual, X. T., Zhu, W. \& Chen, Y. M. Amphiphilic toothbrushlike copolymers based on poly(ethylene glycol) and poly $(\varepsilon-$ caprolactone) as drug carriers with enhanced properties. Biomacromolecules 11, 1331-1338 (2010)

30 Liu, J. Y., Huang, W., Pang, Y., Zhu, X. Y., Zhou, Y. F. \& Yan, D. Y. Hyperbranched polyphosphates for drug delivery application: design, synthesis, and in vitro evaluation. Biomacromolecules 11, 1564-1570 (2010). 